\title{
REGROWTH OF CHLORELLA SOROKINIANA ON RECYCLED MEDIA WITH REPLENISHED NUTRIENTS
}

\author{
A Thesis \\ presented to \\ the Faculty of California Polytechnic State University, \\ San Luis Obispo \\ In Partial Fulfillment \\ of the Requirements for the Degree \\ Master of Science in Civil and Environmental Engineering
}

by

William Hunter Spence

June 2016 
(C)2016

William Hunter Spence

ALL RIGHTS RESERVED 


\section{COMMITTEE MEMBERSHIP}

TITLE: $\quad$ Regrowth of Chlorella sorokiniana on Recycled Media with Replenished Nutrients

AUTHOR: $\quad$ William Hunter Spence

DATE SUBMITTED: June 2016

COMMITTEE CHAIR: $\quad$ Tryg Lundquist, Ph.D., P.E.

Associate Professor of Civil and Environmental Engineering

COMMITTEE MEMBER: Dr. Corinne Lehr, Ph.D.

Associate Professor of Chemistry

COMMITTEE MEMBER: Dr.Yarrow Nelson, Ph.D.

Professor of Civil and Environmental Engineering 


\begin{abstract}
Regrowth of Chlorella sorokiniana on Recycled Media with Replenished Nutrients
\end{abstract}

\author{
William Hunter Spence
}

Growth media recycling during algae cultivation is necessary to increase the efficiency and reduce the cost of biofuel production from algae feedstocks. Without recycling media, the cost of algae based biofuel production would be prohibitively high and large scale algae based biofuel production would not be economically viable. The ratio of media recycled to media wasted assumed for algae farms is generally calculated to maintain salt concentrations below growth inhibitory levels, ignoring the influence of secondary metabolites which might decrease productivity. Secondary metabolites, which include allelopathic or auto-inhibitory biological contaminants, might lead to the accumulation of growth-inhibiting compounds in recycled media used in algae production.

Chlorella sorokiniana (strain DOE1412) was a leading algae biofuel feedstock candidate and has not previously been evaluated for inhibitor production. To test the effects of water recycling on the growth of DOE1412, media was recycled through multiple rounds of algae cultivation. DOE1412 was grown in modified BG11 culture media until reaching the end of linear growth phase, at which point the biomass was removed, nutrients replenished to their initial concentrations, and the recycled culture media used for a subsequent round of growth. The culture media was recycled through five rounds of growth with cultures grown on recycled media compared to controls grown on freshly prepared growth media. Biomass density was monitored via optical density and the specific and productivity growth rates were used to quantify the extent of inhibition. Exploratory work was performed with the goal of identifying potential inhibitory substances produced by DOE1412 during cultivation. Samples of recycled media were analyzed for polyunsaturated fatty acids which have been demonstrated to be inhibitory. The carbohydrates content of used media was analyzed to assess the amount of organic materials shed by DOE1412 into recycled media during growth.

The log phase growth rate $\left(\right.$ day $\left.^{-1}\right)$ of DOE1412 was inhibited by $3 \pm 2 \%, 8 \pm 1 \%, 10 \pm 2 \%$, and $18.6 \pm 0.9 \%$ when grown in media recycled 1-4 times, respectively, with a $99 \%$ level of confidence that inhibition was observed in each round of regrowth. The productivity growth rate $\left(\mathrm{OD}_{750} /\right.$ day) of DOE1412 was not inhibited in media recycled 1-3 times. The productivity growth rate of DOE1412 was inhibited by $13 \pm 3 \%$ when grown in media recycled 4 times with a $99 \%$ level of confidence that inhibition was observed.

Zinc was found to accumulate in the recycled media to potentially toxic levels $(>0.09 \mathrm{mg} / \mathrm{L}$ ), therefore it is uncertain if the observed inhibition was due to an accumulation of inhibitory secondary metabolites or the accumulation of zinc. 
Two inhibitory polyunsaturated acids, linoleic and linolenic acid, were identified in media recycled 4 times. The carbohydrate content of recycled media fluctuated between 8-10\% of total fixed carbon in media recycled 1-3 times and increased to $18 \%$ in media recycled 4 times. However, changes observed in media recycled 4 times may have been due to improper storage of used media. 


\section{ACKNOWLEDGMENTS}

I would like to express my sincere gratitude to:

All of the ENVE 405 students for their help with this research:

Simone Mangini, Melissa Pasa, Lindsay Decosta, Keenan Burns, Mike Ward, and everyone else who assisted but was not mentioned here,

Trygve Lundquist for providing guidance and challenging projects which helped me grow and mature throughout my graduate studies,

Dr. Corinne Lehr for recommending me for this graduate program and research project and also for guiding me through my undergraduate studies at Cal Poly,

Dr. Yarrow Nelson for serving on my thesis committee and providing his valuable input,

Braden Crowe for assisting with my project, providing constructive criticism when needed, and helping me through challenging points in my research.

To all the graduate students who made my time in lab so enjoyable: Alec Roberts, Carter Reiff, Garret Murawsky, Christopher Swain, Erik Zardouzian, Christian Bowen, Chri Pittner, Tiffany Razc, Erik Krikorian, and Lauren Parker.

And special thanks to James Kelley, Shelley Blackwell, John Rivera, Dr. Rebekah Oulton, Lili Gevorkian, and Kimmy Pugel.

And to my loving and supportive family. 


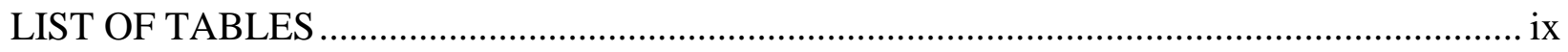

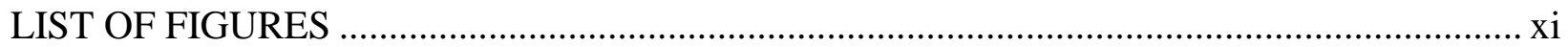

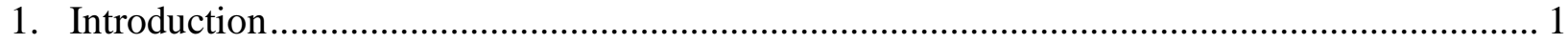

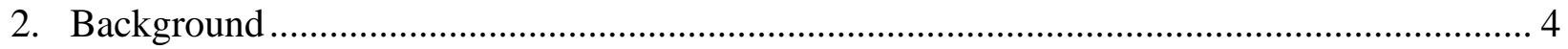

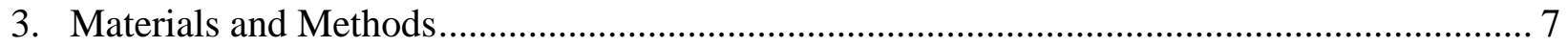

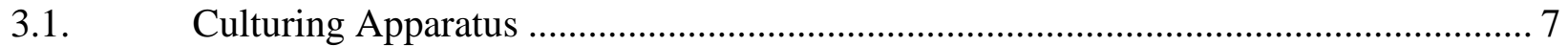

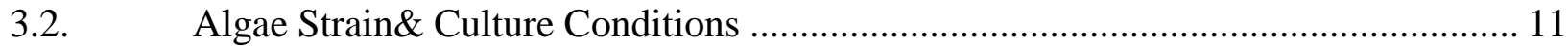

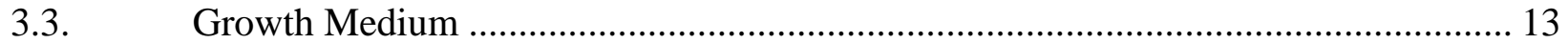

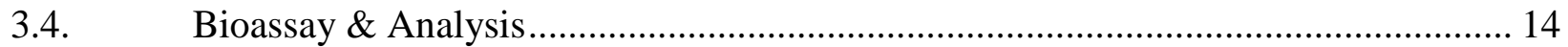

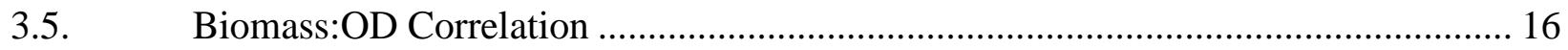

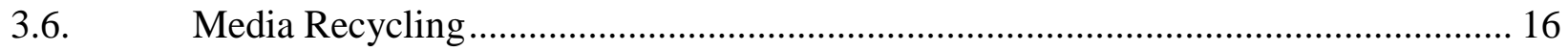

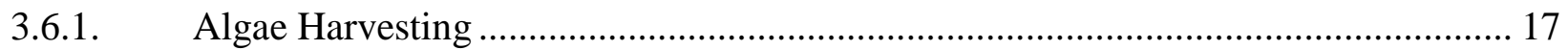

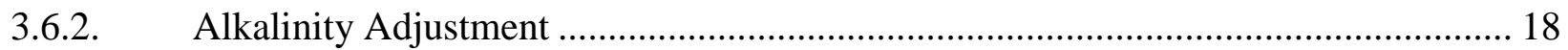

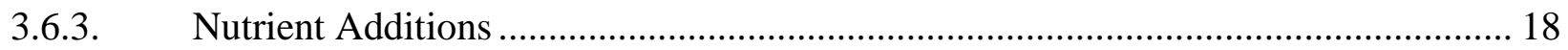

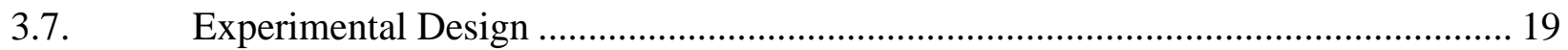

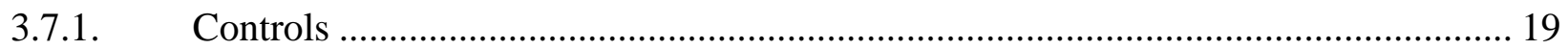

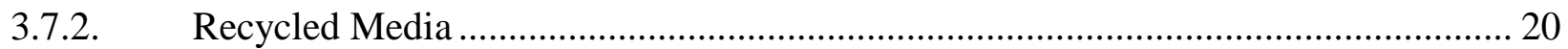

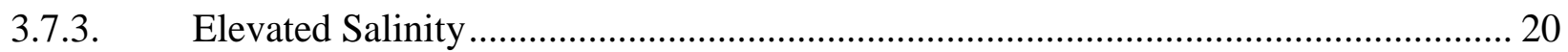

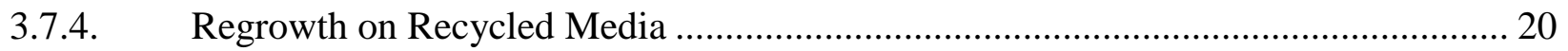

3.8. Potential Inhibitor Analysis \& Identification ........................................................... 23

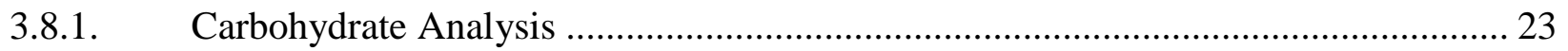

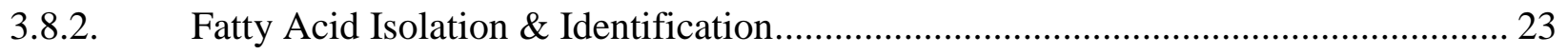

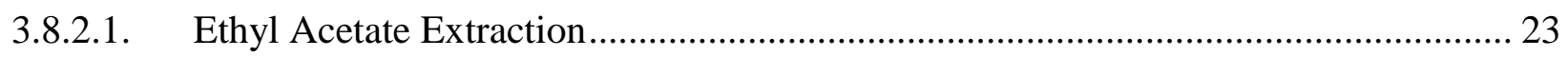

3.8.2.2. Evaporation of Ethyl Acetate Extract ..................................................................... 24

3.8.2.3. Transesterification \& GC-MS Analysis ………..................................................... 25

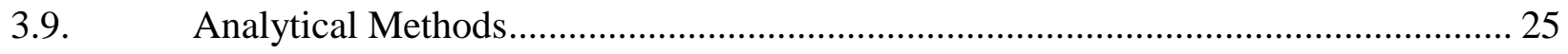

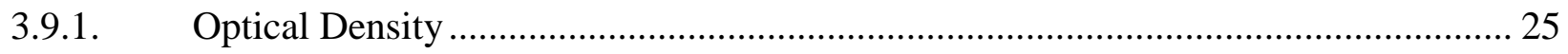

3.9.2. Macro-nutrient and Alkalinity Measurements ......................................................... 26

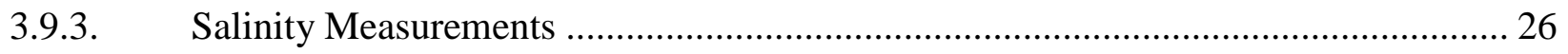




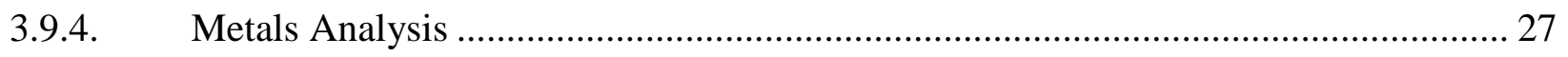

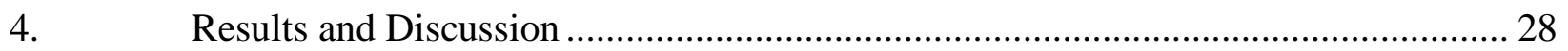

4.1. Used Media Characterization ....................................................................... 28

4.1.1. Nutrient Levels at End of Cultivation............................................................. 28

4.1.2. Alkalinity Measurements at End of Cultivation .................................................. 29

4.1.3. Salinity Measurements at End of Cultivation..................................................... 30

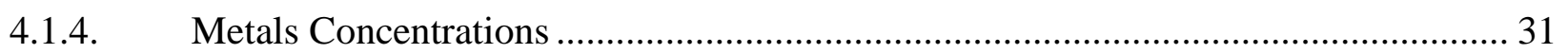

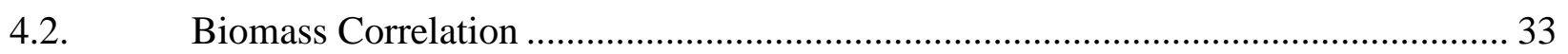

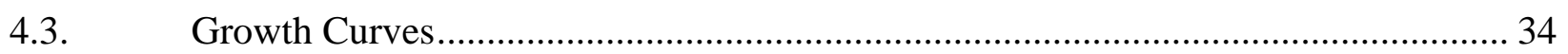

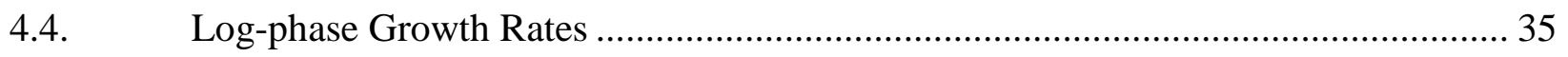

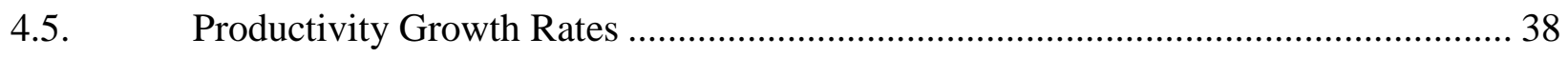

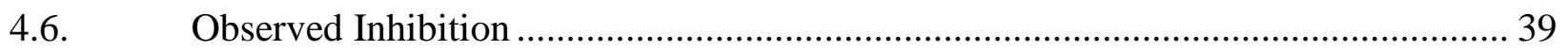

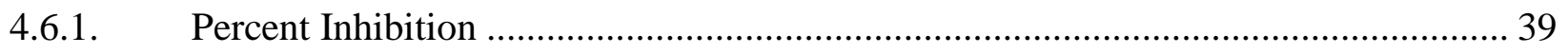

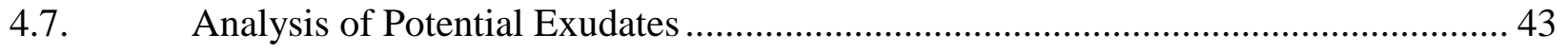

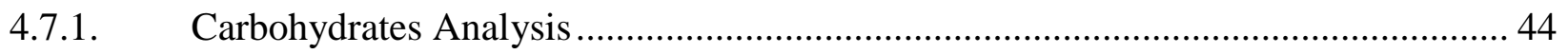

4.7.2. Fatty Acid Isolation \& Identification............................................................ 46

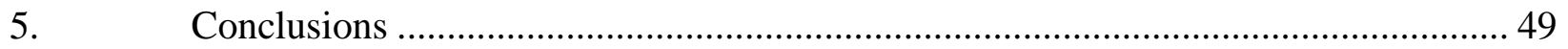

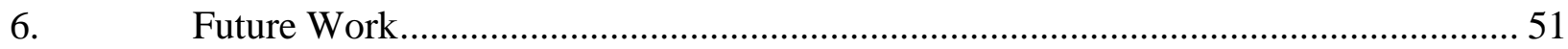

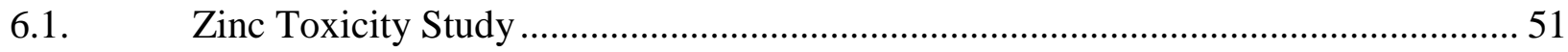

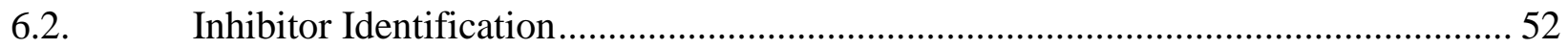

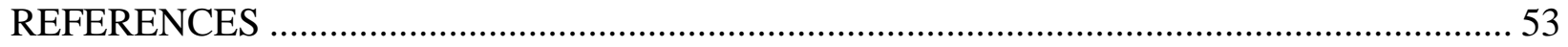

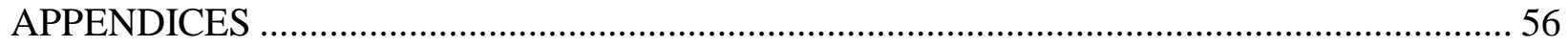

Appendix A: Trace Metal Stock Solution used in Modified BG11 Media Recipe ..................... 56 


\section{LIST OF TABLES}

Table

Page

Table 1: Nutrient Stock Solutions and volumes used to prepared the modified BG11 medium. All nutrient stock solutions were prepared with deionized water and American Chemical Society (ACS) certified salts. Stock nutrient additions to media were carried out in the order listed below. Nutrient Concentrations of Trace Metal solution are listed in Appendix A

Table 2: The round of growth, number of experimental replicate cultures grown on recycled media, the number of control replicate cultures grown on fresh modified BG11 media, and the degree to which the used media had been recycled.

Table 3: The analytical methods for all nutrient, alkalinity, and AFDW measurements (APHA Standard Methods 1995).

Table 4: Concentration of residual sodium nitrate and dipotassium phosphate measured in used media at the end of each round of growth. Percentages of residual nitrogen and phosphorus were calculated with respect to values in the modified BG11 media recipe. Residual nitrogen and phosphorus ions present in the Round-5 used media and used modified BG11 eith elevated salinity were not measured. Residual nitrate and phosphate

ions were measured using procedures cited in section 3.5.2.

Table 5: Alkalinity of Round-1 and Round-3 used media. These measurements were compared to measurements obtained from freshly prepared modified BG11 media taken at 
time of analysis to assess the excess amount of alkalinity produced during cultivation. All value are represented as $\mathrm{CaCO}_{3}$ equivalents

Table 6: Salinity of recycled media with replenished nutrients, modified BG11 media, and modified BG11 media with elevated salinity.

Table 7: Residual metals content of Round-4 used media and the corresponding concentration present in modified BG11 media. The accumulation is calculated as a percentage in respect to modified BG11 media.

Table 8: Percent inhibition, degrees of freedom, calculated t-value, critical t-value, and respective confidence interval for all specific and productivity growth rates obtained from Rounds 2-5 of regrowth on recycled water and the elevated salinity experiment.

Table 9: FAMEs detected in Round-5 used media and their respective correlations and estimated concentrations. The correlation percentage represents the degree that the massspectrometer signal for each substance below matches the respective database signal. Commons names are provided in parenthesis for each substance when available. .46 


\section{LIST OF FIGURES}

Figure

Page

Figure 1: Left: Diagram of assembled algae growth vessel: (A) 500-mL square silica glass bottle. (B) \#3 rubber stopper with drilled inlet and outlet. (C) Pasteur pipette inserted into gas flow inlet. (D) Cotton fiber plug. (E) Disk Filter. (F) Flexible tubing. (G) Magnetic stir bar. Right: Photo of assembled growth vessel. .8

Figure 2: Top: Plan view diagram of the culturing apparatus (Gas manifolds not shown). Center baffle was comprised of a heavy black plastic sheet suspended by a length of wood and weighed down by a galvanized metal rod. Bottom: Top-down photo of culturing apparatus.

Figure 3: Photomicrograph of Chlorella sorokiniana used in the present research at 1000x magnification (Lindsay Decosta, CalPoly)

Figure 4: Process flow diagram of the step-by-step procedure used to recycle media through multiple rounds of algae cultivation.

Figure 5: Correlation of $\mathrm{OD}_{750}$ vs AFDW for Chlorella sorokiniana. .34

Figure 6: Example growth curve. The logarithmic growth phase was characterized by a linear trend in the $\operatorname{lnOD}_{750}$ plot while the productivity phase was characterized by a linear trend in the $\mathrm{OD}_{750}$ plot. This particular growth curve was obtained from replicate Control-1 of Round-5 of regrowth. 
Figure 7: Specific growth rates obtained for control and experimental conditions from Rounds 1-5 of regrowth and the salinity experiment. Error bars indicate mean $+/-$ the sample standard deviation of specific growth rate.

Figure 8: Productivity growth rates obtained from Round 2-5 of regrowth and the salinity experiment. Error bars indicate mean $+/$ - standard deviation of productivity growth rate. .38

Figure 9: Percent inhibition of log-phase growth rates obtained from Rounds 1-5 of regrowth and the salinity experiment. Error bars represent the sample standard deviation of percent inhibition in both the positive and negative directions.

Figure 10: Percent inhibition of productivity in Round-5 of regrowth and the elevated salinity experiment. Error bars represent the sample standard deviation in the positive and negative directions

Figure 11: Hydrolyzed and non-hydrolyzed carbohydrate content of used media. .44 


\section{Introduction}

The widespread use of fossil fuels has led to unsustainable environmental consequences such as ocean acidification and climate change. These impacts along with the declining global supply of petroleum reserves have motivated a search for economical and environmentally sustainable alternatives to fossil fuels such as fungible liquid transportation biofuels (Lardon, 2009). However, widespread use of first and second generation biofuels would have negative and unsustainable environmental impacts through competition with food crops for fertilizer, pesticides, water, and arable land (Lardon, 2009).

Autotrophic aquatic microalgae are of interest as a third generation biofuel feedstock because they have the potential to utilize sources of land, water, and nutrients which do not compete with edible food crop production (Lardon, 2009) while converting sunlight into biomass with a higher efficiency when compared to traditional oilseed feedstocks (Medipally, 2015). Algae cultivation systems can be implemented in deserts or salt flats where climate and soil quality is prohibitively unfavorable to terrestrial crop production while the water which can be used to fill such systems can be saline, brackish, produced water from oil wells, or other sources of low quality water (DOE, 2010). However, while algae-derived biofuels do have the potential to meet a significant portion of domestic energy demands, significant improvements in current technologies are needed (Davis, 2011). For example, to meet 5 percent of U.S. demand for transportation fuels using current technologies would require 123 billion liters of water, placing unsustainable demand on available water resources (NRC, 2012). One such avenue where this demand can be 
substantially reduced, thereby increasing the sustainability of algal biofuels, is by the recycling of harvest water after cultivation (NRC, 2012).

Idealized process trains used in techno-economic analyses assume water is recycled to increase the efficiency of algal cultivation systems and decrease costs of biomass production. In effect, water recycling is essential to the commercial viability and sustainability of large-scale algae cultivation systems given the sheer volume of water such systems require (DOE, 2010). Further work is thus needed to determine how recycling water may affect the efficiency of such systems.

To explore how water recycling may effect algae growth, bench-scale experiments are necessary to eliminate confounding factors and isolate experimental variables so that hypothesis can be rigorously tested. Conversely, open-pond systems are subject to a high degree of variability in environmental conditions which may mask the effects of water recycling. Therefore, pilot-scale studies are necessary to generate comparable results to real world scenarios given that the effects of water recycling may not be significant enough to impact large scale open pond systems. This project aims to explore how water recycling affects algae cultivation by utilizing both bench and pilot scale experiments in conjunction with one another.

Biological inhibitor contamination has been shown to pose a significant barrier to cost-effective large-scale algal biomass production technologies (Wanq, 2013). Such biological inhibitors, which may or may not be produced by different strains of algae during cultivation, are difficult to identify. The purpose of this study is to explore the effects of water recycling on algal growth in a controlled bench scale cultivation reactors so that all other variables (e.g., salinity, alkalinity, 
nutrient loading, $\mathrm{pH}$, light intensity, and temperature) besides biological inhibitor accumulation can be controlled or accounted for. The results of this study will better elucidate the degree by which biological inhibitor accumulation might affect large scale algae cultivation systems.

Here, the effects of water recycling are tested on a monoculture of Chlorella sorokiniana (DOE1412). Strain DOE1412 is of interest as a leading biofuel candidate by the National Alliance for Advanced Biofuels and Bio-products (NAABB) due to its ideal lipid profile, growth potential on low cost media, low ash content, and optimal growth over a broad temperature range $\left(5^{\circ} \mathrm{C}\right.$ through $\left.40^{\circ} \mathrm{C}\right)(\mathrm{NAABB}, 2010)$. 


\section{Background}

Water recycling in large-scale algae cultivation systems can lead to the accumulation of salts, chemical flocculants used in harvesting, or biological inhibitors produced by algae strains themselves which may cause decreases in algae productivity (DOE, 2010). Such effects must be studied in benchtop and pilot scale systems to assess the optimal level of recycling for such large-scale algae cultivation systems. The blowdown water wasted to maintain salt content, chemical flocculants, or growth inhibitory substances within or below target concentrations would also need to be treated and disposed of properly, thus adding further cost to algae biomass production (DOE, 2010). For these reasons, further studies are needed to assess the proportion of water recycled to water wasted to optimize the cost of algae biomass production.

There are multiple pathways which can lead to an accumulation of biological inhibitors in recycled water. Allelopathy is one such pathway. Allelopathy is defined as the direct or indirect harmful effect of one species on another by the production and excretion of chemically active compounds (Rice, 1974). Organisms will produce allelopathic compounds to inhibit the growth of other organisms to gain a competitive advantage. Evidence of allelopathy between competing organisms has been demonstrated in multiple algal species including Chlorella vulgaris (Fergola, 2007), Cladosiphon okamuranus (Kakisawa, 1988), and Ishige sinicola (Hirao, 2012).

Allelopathy is also known to occur between species of algae and bacteria due to competition for nutrients (Legrand, 2003). 
A second potential pathway of growth inhibition is the production of auto-inhibitory substances. This auto-inhibition is distinct from allelopathy in that such substances act on the species that produce them. Auto-inhibition has been demonstrated in Chlorella pyrenoidosa (Ikawa, 1997) and in green algae species within the family Volvocaceae (Harris, 1971). This pathway is significant in the case of axenic or monocultures which do not harbor multiple competitive species of organisms. Past works have isolated and identified auto-inhibitory substances produced by Chlorella during cultivation. Of interest to this research are polyunsaturated fatty acids (PUFAs), particularly linoleic and linolenic acid, which have been demonstrated to be potent growth inhibitors to Chlorella either directly or by their degradation products (Ikawa, 1997)(Yamada, 1994).

While other species of Chlorella have been found to produce auto-inhibitory substances, DOE1412 has not yet been tested for such substances. How water recycling may affect the growth of DOE1412 is currently unknown. Therefore, it is necessary to investigate how water recycling may affect the growth of DOE1412 in order to assess its viability as a commercial strain. Given that large-scale cultivation systems are governed largely by growth rates and not maximum carrying capacities, this research focuses on the use of growth rates as the primary metric for evaluating culture performance in the search for inhibition.

The goal of this research was to investigate how media recycling might affect DOE1412 by evaluating rates of culture growth. This goal can be broken down into a series of questions which are addressed by this research are as follows: 
- Is the growth of DOE1412 inhibited by recycling growth media?

- Does the cultivation of DOE1412 lead to the production of inhibitory compounds?

- Do inhibitory compounds accumulate in recycled water?

- Are the effects of inhibitory compounds more prominent in the unlimited phase of batch growth or in the light-limited linear productivity stage?

- Finally, as a preliminary form of inhibitory compound identification, can any inhibitory compounds be classified as carbohydrates or lipids? 


\section{Materials and Methods}

To test the effects of water recycling on algae growth, media was reused in multiple batches of algae cultures in a controlled laboratory setting. Concentrations of dissolved reactive phosphorus, nitrate, metals, alkalinity, and salinity of used media were measured and nutrients replenished between each round of reuse. Algae growth was monitored via optical density and growth rates were compared to control cultures using a one-tailed paired t-test.

\subsection{Culturing Apparatus}

Each culture bottle (500-mL square soda-lime-silica glass, 5.72-cmx5.72-cmx27.31-cm, Cat. \# QDRA17C, Specialty Bottle, city state ) was sealed with a \#3 rubber stopper (Cat. \# 4-130E, Fisher Scientific) with drilled inlet and outlet holes for gas flow (Figure 1). A 33.7-cm long borosilicate glass Pasteur pipette (Cat. \# 7095B-NMR, Sigma-Aldrich) was inserted in the inlet of the stopper and the outlet was plugged with cotton. The culture was sparged with an adjustable mixture of carbon dioxide which was provided via a disk filter $(0.20-\mu \mathrm{m}$ pore size, Cat. \#: 17764Q, Sartorius) connected by SPX-50 silicone tubing (Cat. \#: ABX00012, SaintGonain Performance Plastics) to the inserted Pasteur pipette and by TYGON ${ }^{\circledR}$ tubing (Cat. \#: AAB00007-CP, Cole-Parmer) to the gas manifold of the growth apparatus. The cultures were stirred with a magnetic stir bar (3.8-cm x 0.7-cm, Teflon-coated, Cat. \#: S68070, Fisher Scientific) at 260 RPM via the magnetic stir plates. RPM was monitored and adjusted using the digital display of the magnetic stir-plates. 


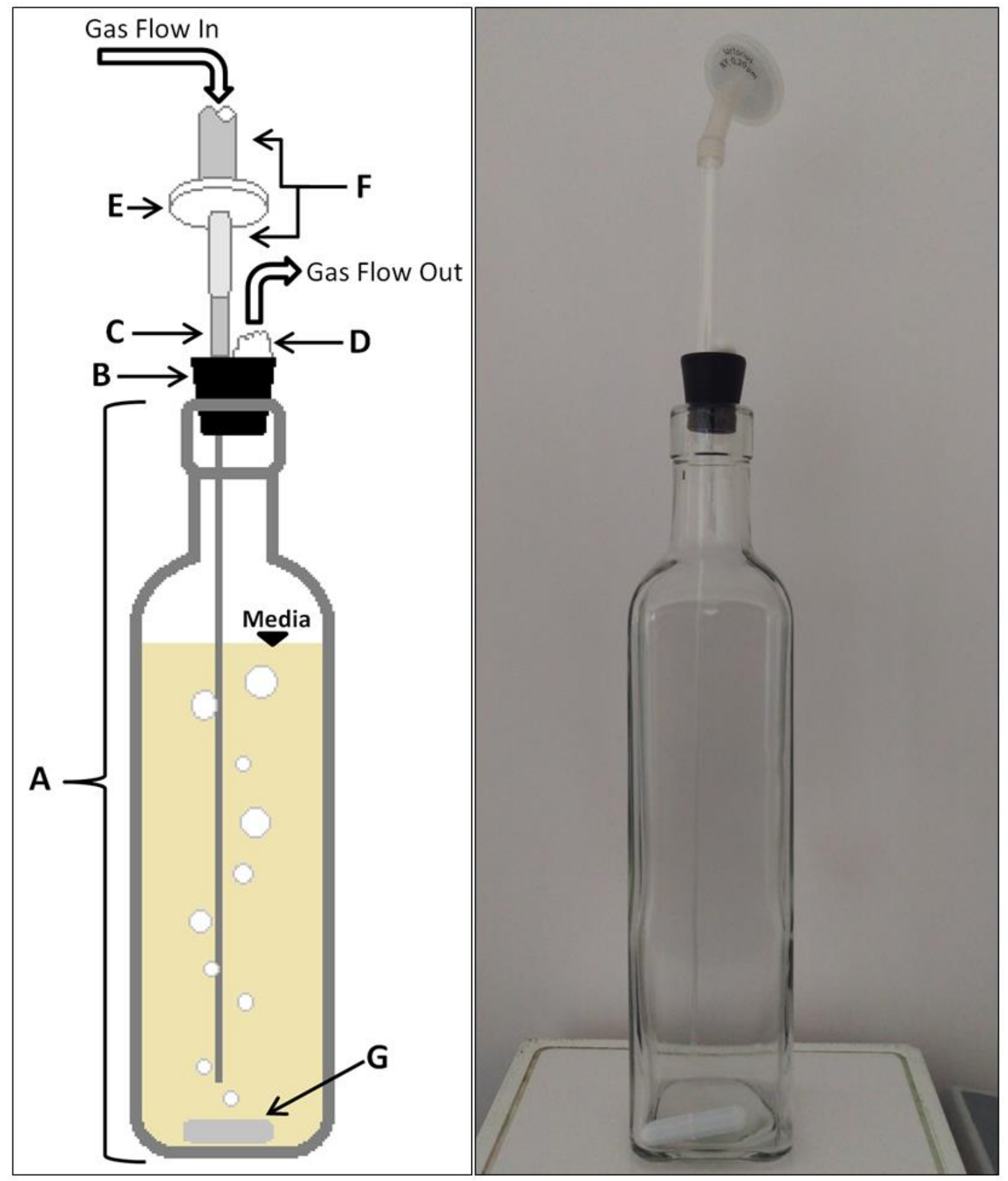

Figure 1: Left: Diagram of assembled algae growth vessel: (A) 500-mL square silica glass bottle. (B) \#3 rubber stopper with drilled inlet and outlet. (C) Pasteur pipette inserted into gas flow inlet. (D) Cotton fiber plug. (E) Disk Filter. (F) Flexible tubing. (G) Magnetic stir bar. Right: Photo of assembled growth vessel. 
Light was provided by two light fixtures containing four fluorescent lamps each ("4 Foot 4 Lamp” High Output T5 Fixtures, F54T5/HO Grow Spectrum fluorescent lamps, HTG Supply, Commerce City, Colo.) mounted horizontally and opposite to each other on either side of the glass water bath. Two multiple-station magnetic stir plates (Multipoint 15, Cat. \# 50093538, Cimarec) were centered between the light fixtures to provide a total of 20 stir positions (Figure 2). Culture bottles were placed on stir positions in a water bath which dampened changes in culture temperature. The water bath was an aquarium $(122-\mathrm{cm} \times 30.5-\mathrm{cm} \times 30.5-\mathrm{cm}$, soda-limesilica glass) set on top of the stir plates with two circulation pumps (MAXI-JET 400, Marineland, Blacksburg, VA) mounted to the side walls. Two gas supply manifolds with flow control valves for each bottle provided a mixture of approximately $5 \%$ carbon dioxide in air to each bottle via tubing and Pasteur pipette sparging rod. Prior to reaching the manifold, the $\mathrm{CO}_{2^{-}}$ air mixture passed through a humidifier (sealed bottle containing deionized water and a sparging stone). The $\mathrm{CO}_{2}$-air mixture was comprised of industrial-grade $\mathrm{CO}_{2}$ and house-air purified by an activated carbon filter. The $\mathrm{CO}_{2}$ and air was mixed using a gas mixer (Model 7400, Matheson, Newark, UK). 

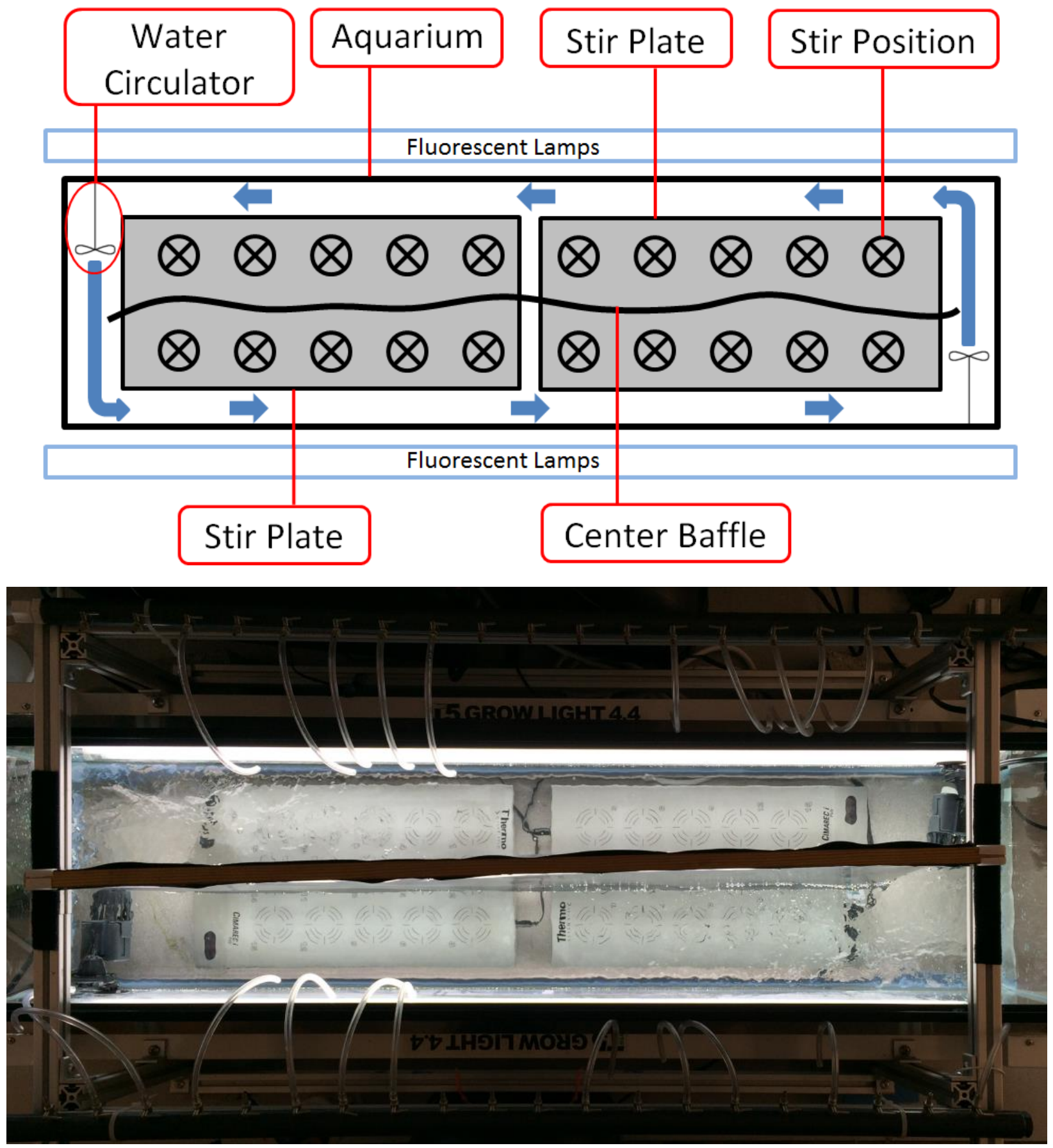

Figure 2: Top: Plan view diagram of the culturing apparatus (Gas manifolds not shown). Center baffle was comprised of a heavy black plastic sheet suspended by a length of wood and weighed down by a galvanized metal rod. Bottom: Top-down photo of culturing apparatus. 


\subsection{Algae Strain\& Culture Conditions}

A strain of Chlorella sorokiniana known as DOE1412 (NAABB, 2014), was first isolated by Dr. Juergen Polle (Brooklyn College) from fresh Texas surface waters. For the current project, DOE1412 was purchased in March 2014 on a slant containing modified BG11 agar (UTEX Culture Collection of Algae).

DOE1412 backup cultures were propagated from culture slants in 150-mL Erlenmeyer flasks containing 50-100 mL of modified BG11 media and sealed with a drilled rubber stopper with cotton plug and capped with aluminum foil. Backup cultures were stored in indirect-light provided by the nearby culturing apparatus at room temperature $\left(19-26^{\circ} \mathrm{C}\right)$. These cultures served as backups in case of contamination in subsequent batches.

The backup cultures were used to inoculate stock cultures comprised of $450 \mathrm{~mL}$ of modified BG11 media in the 500-mL square culture bottles. The square culture bottles were used as the primary growth vessel for stock cultures and experimental cultures of DOE1412 throughout this research. These cultures were maintained in the culturing apparatus described in Section 3.1 at room temperature $\left(19-26^{\circ} \mathrm{C}\right)$ under continuous light conditions of approximately $350-400$ $\mu \mathrm{mol} / \mathrm{m}^{2}$-sec. All stock and experimental cultures were maintained at $\mathrm{pH} 6.5$ by adjusting the $\mathrm{CO}_{2}$ :air sparging mixture via the gas mixer (Section 3.1).

Stock and experimental cultures were routinely monitored via microscopy for typical DOE1412 morphology of 3-6 $\mu$ m diameter spherical cells, partially green in color (Figure 3). 


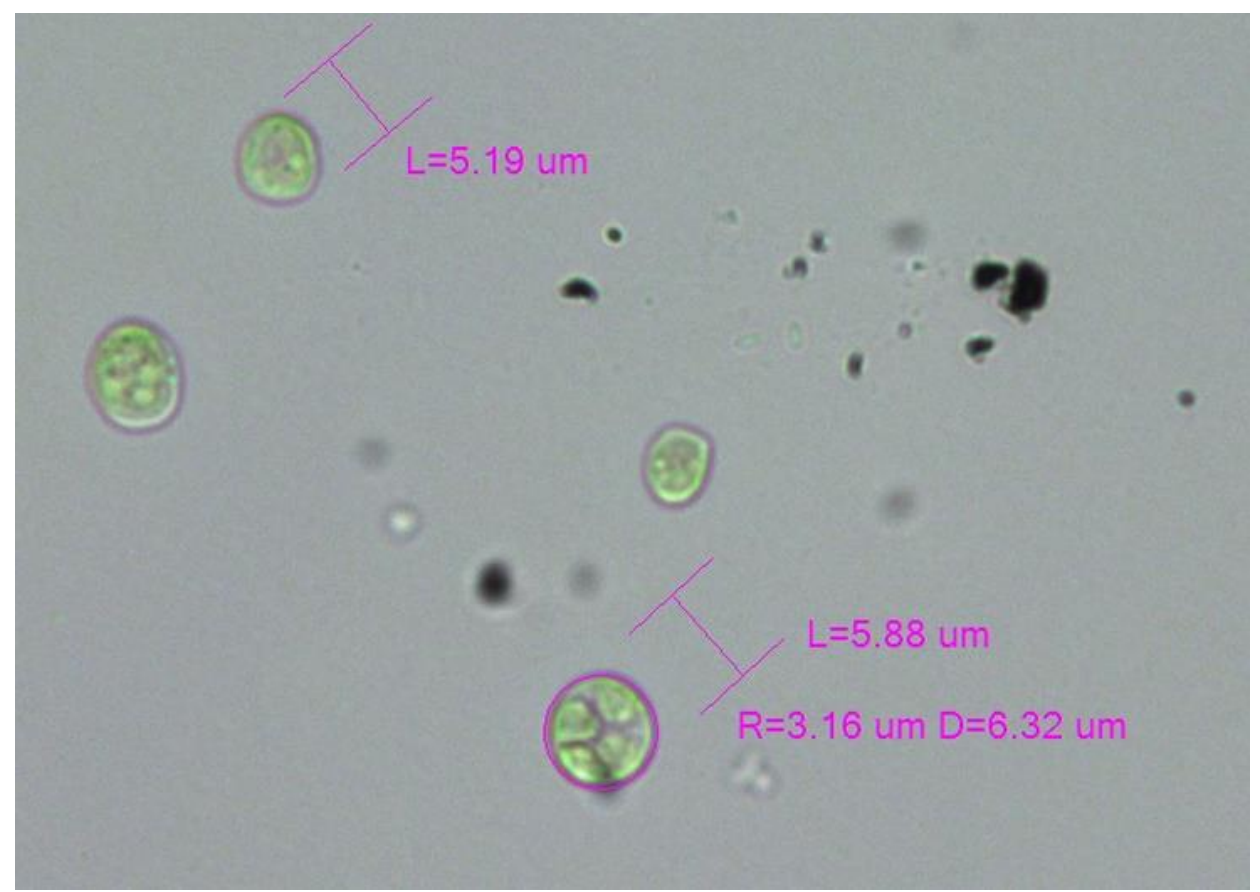

Figure 3: Photomicrograph of Chlorella sorokiniana used in the present research at 1000x magnification (Lindsay Decosta, CalPoly).

All experimental cultures were inoculated from a single stock culture of DOE1412. Stock cultures were maintained in log-phase until three consecutive batches of growth had specific growth rates within a five percent relative standard deviation of each other before inoculation of experimental cultures to promote more consistent culture conditions in the inocula. All cultures were inoculated to an initial density of 0.06-0.10 optical density at $750 \mathrm{~nm}$ (Section 3.4.1). 


\subsection{Growth Medium}

Table 1: Nutrient Stock Solutions and volumes used to prepared the modified BG11 medium. All nutrient stock solutions were prepared with deionized water and American Chemical Society (ACS) certified salts. Stock nutrient additions to media were carried out in the order listed below. Nutrient Concentrations of Trace Metal solution are listed in Appendix A.

\begin{tabular}{|c|c|c|c|c|}
\hline Stock Solution & $\begin{array}{l}\text { Chemical } \\
\text { Formula }\end{array}$ & $\begin{array}{l}\text { Concentration of } \\
\text { consituent (g/L) }\end{array}$ & $\begin{array}{c}\text { Volume added } \\
\text { to deionized } \\
\text { water to make } 1 \\
\text { L of medium } \\
(\mathrm{mL})\end{array}$ & $\begin{array}{c}\text { Concentration } \\
\text { in final } \\
\text { medium } \\
(\mathrm{mM})\end{array}$ \\
\hline \multirow{2}{*}{$\begin{array}{l}\text { Iron ammonium } \\
\text { citrate solution }\end{array}$} & $\mathrm{C}_{6} \mathrm{H}_{8} \mathrm{O}_{7}$ & 6 & \multirow{2}{*}{3.0} & 0.094 \\
\hline & $\mathrm{C}_{6} \mathrm{H}_{11} \mathrm{FeNO}_{7}$ & 6 & & 0.064 \\
\hline Sodium nitrate & $\mathrm{NaNO}_{3}$ & 150 & 10 & 17.6 \\
\hline $\begin{array}{l}\text { Dipotassium } \\
\text { phosphate }\end{array}$ & $\mathrm{K}_{2} \mathrm{HPO}_{4}$ & 31.0 & 3.0 & 0.53 \\
\hline $\begin{array}{l}\text { Magnesium } \\
\text { sulfate } \\
\text { heptahydrate }\end{array}$ & $\mathrm{MgSO}_{4} \cdot 7 \mathrm{H}_{2} \mathrm{O}$ & 75.0 & 1.0 & 0.3 \\
\hline $\begin{array}{c}\text { Calcium chloride } \\
\text { dihydrate }\end{array}$ & $\mathrm{CaCl}_{2} \cdot 2 \mathrm{H}_{2} \mathrm{O}$ & 147 & 1.0 & 0.24 \\
\hline Sodium carbonate & $\mathrm{Na}_{2} \mathrm{CO}_{3}$ & 106 & 1.0 & 0.19 \\
\hline $\begin{array}{l}\text { EDTA disodium } \\
\text { salt }\end{array}$ & $\begin{array}{c}\text { EDTA- } \\
\mathrm{Na}_{2} \cdot 2 \mathrm{H}_{2} \mathrm{O}\end{array}$ & 0.85 & 1.0 & 0.023 \\
\hline $\begin{array}{l}\text { Trace Metal } \\
\text { Solution }\end{array}$ & Various & Appendix A & 1.0 & NA \\
\hline
\end{tabular}


Modified BG11 media was prepared from a series of aqueous stock solutions (Table 1). All stock nutrient additions were added directly into filter disinfected deionized water using 0.1-5.0 $\mathrm{mL}$ sterile plastic syringes and sterile syringe filters $(0.22-\mu \mathrm{m}$ pore size, Cat. \# SLGP033RS, EMD Millipore, Billerica, Mass.).

Heat and pressure from autoclave sterilization was found to induce mineral precipitation in the final medium. To reduce this precipitation, deionized water and all additions of nutrient stock components used to prepare the final medium were filter-disinfected using the methods described above. Precipitation in the final medium was substantially reduced using this method.

\subsection{Bioassay \& Analysis}

The log-phase growth rate $(\mu)$ was estimated from log-transformed plots of $\mathrm{OD}_{750 \mathrm{~nm}} v s$ time in hours (Equation 1):

$$
\mu=\frac{\ln \left(X_{T_{1}}\right)-\ln \left(X_{T_{0}}\right)}{T_{1}-T_{0}}
$$

where $\mathrm{X}$ is $\mathrm{OD}_{750 \mathrm{~nm}}$ and $\mathrm{T}$ is time in days.

While log-phase growth rate represents the rate of growth during log-phase, linear-phase growth rate describes the rate of growth during linear-phase, which occurs when a culture is limited only by light due to high cell concentration. Light limited growth is the normal condition of raceway pond cultures and thus may better predict results in scaled-up outdoor race way cultures. Here we 
define the linear-phase growth rate as productivity growth rate, or productivity for short. Linearphase growth rates were estimated from normal plots of biomass measured as $\mathrm{OD}_{750}$ vs time in hours (Equation 2):

$$
\text { Linear phase growth rate }=\frac{X_{T_{1}}-X_{T_{0}}}{T_{1}-T_{0}}
$$

For estimation both specific growth rates and productivity, $\mathrm{T}_{0}$ and $\mathrm{T}_{1}$ were the earliest and latest data points on the linear regression of selected linear periods. Linear periods used to calculate growth rates were determined by selecting for the linear trend line which produced the highest Rsquared values.

Log-phase growth rates were obtained from the log-phase of growth which is characterized by a linear region within log-transformed plots of $\mathrm{OD}_{750}$. Productivity growth rates were obtained from the linear-phase of growth, characterized by a linear region of normal plots of $\mathrm{OD}_{750}$.

Growth rates were the sole means of observing the performance of algae growth, and growth inhibition could only be observed as a difference in specific growth rate or productivity between two sets of cultures. 


\subsection{Biomass:OD Correlation}

The relationship between $\mathrm{OD}_{750}$ and the concentration of DOE1412 biomass as ash-free dry weight (AFDW, Table 2) was determined for a set of five replicate cultures with samples collected periodically throughout a single batch cultivation.

\subsection{Media Recycling}

To reuse media, biomass was removed via centrifugation and filtration and nutrients and alkalinity was restored to that of modified BG11 media. To restore nutrients and alkalinity to initial levels, residual nutrients in used media must first be quantified and the alkalinity destroyed by titrating with hydrochloric acid. The following sections describe procedures and methods used for removing algal biomass, destruction of accumulated alkalinity, measurements of residual nutrient levels, and replenishment of nutrients in used media.

The following list defines terms used in describing the experimental procedures.

Fresh media: Freshly prepared (less than 12 hours old) modified BG11 media.

Used media: Media collected at end of one cycle of cultivation with algae biomass removed (Section 3.5.1).

Recycled media: Used media with alkalinity adjusted and nutrients replenished (Section 3.5.4).

Round: One full batch cycle of algae cultivation.

Regrowth: Describes the cultivation of algae on recycled media. 
Round 1-5 used media: Describes the number of times a batch of used media has been recycled for algae cultivation (e.g., Round-5 used media is a batch of water obtained after five consecutive cycles of algae cultivation).

Round 1-5 recycled media: Describes the batch of recycled media used in each round of cultivation (e.g., Round-5 recycled media was prepared from Round-4 used media).

Round 1-5 of regrowth: Describes regrowth on Round 1-5 recycled media.

\subsubsection{Algae Harvesting}

After each round of cultivation, replicate algae cultures were pooled and the biomass was harvested after each round of cultivation via centrifugation at $6000 \mathrm{rpm}$ for 20 minutes at $20^{\circ} \mathrm{C}$ (J-LITE ${ }^{\circledR}$ JLA-9.1000 Rotor, Beckman Coulter, Brea, Calif.). The supernatant was decanted and frozen $\left(-20^{\circ} \mathrm{C}\right)$ for further processing.

Residual suspended solids were later removed from the supernatant by multiple vacuum filtration steps as follows. The supernatant was initially filtered through $1.0-\mu \mathrm{m}$ pore size filter disks (Cat. \#: 09-804-90C, Fisher Scientific) before a second filtration step through 0.22- $\mu \mathrm{m}$ pore size filter disks (Cat. \#: GPWP09050, Millipore). All filtration steps were performed using a 90-mm diameter vacuum filtration assembly with fritted glass support and ground glass joint (Cat. \#: K953835-0090, Fisher Scientific). This process was repeated between each consecutive round of growth. 


\subsubsection{Alkalinity Adjustment}

The use of nitrate as a source of nitrogen led to an increase in alkalinity during growth. This increase in alkalinity was caused by the production of hydroxide ions by the algae during nitrogen assimilation. To better control the $\mathrm{pH}$ and keep alkalinity constant in consecutive rounds of regrown, alkalinity of used media was initially destroyed by adjusting used media to $\mathrm{pH} 4.5$ with drop-wise additions of hydrochloric acid (37\% w/w, Cat. \#: A144C212, Fisher Scientific). Alkalinity was then replenished to equivalent levels in fresh media using the sodium carbonate stock solution in the amount shown in Table 1. This allowed for the recycled media to have an equivalent amount of alkalinity at the start of cultivation as fresh media.

\subsubsection{Nutrient Additions}

All nutrients were replenished from modified BG11 stock nutrient components to modified BG 11 concentrations (Section 3.3). Volumes of nutrient stock solutions needed were calculated using Equation 3:

$$
V_{s}=\frac{V_{r}\left(C_{B G 11}-C_{r}\right)}{C_{s}}
$$

where $\mathrm{V}_{\mathrm{s}}$ is the volume of stock nutrient solution to be added, $\mathrm{V}_{\mathrm{r}}$ is the volume of recycled media, $\mathrm{C}_{\mathrm{r}}$ is the residual concentration of the constituent in used BG11 media after cultivation, $\mathrm{C}_{\mathrm{BG} 11}$ is the concentration of the respective constituent in fresh modified BG11 media, and $\mathrm{C}_{\mathrm{s}}$ is 
the concentration of the respective constituent in the appropriate nutrient stock solution listed in

\section{Table 1.}

All other nutrients, with the exception of trace metals, were added in proportional amounts to sodium nitrate or dipotassium phosphate, which ever was proportionally lower when compared to fresh media. For example, if the percentage of phosphorus was lower than that of nitrogen when compared to modified BG11 media, then all other nutrients were replenished with the same percentage-wise addition to that of phosphorus. This was done to ensure no un-quantified nutrients were present in recycled media at growth-limiting concentrations while also preventing mitigating their accumulation. The full volume of trace metal stock solution (Table 1) was added to the used media.

\subsection{Experimental Design}

The following sections describe the process by which regrowth experiments were conducted and the experimental and control conditions used to test algae regrowth on recycled media.

\subsubsection{Controls}

Experimental controls were used during each round of regrowth on recycled media. Controls bottles contained only fresh modified BG11 media. Control bottles were incubated simultaneously with experimental bottles in the same cultivation apparatus (Section 3.1). The number of control replicates used was equal to the number of experimental replicates used or in each respective round of regrowth. 


\subsubsection{Recycled Media}

Recycled media was prepared as described in Section 3.6.

\subsubsection{Elevated Salinity}

Multiple rounds of media recycling led to an accumulation of salts. Thus, a second experiment was designed to test the effects of salinity on algal growth. This experiment consisted of modified BG11 media with salinity content elevated to equivalent levels present in the Round-5 recycled media. Using a 2.0-M NaCl solution as described in Section 3.3. The $\mathrm{NaCl}$ solution was prepared from solid $\mathrm{NaCl}$ (Cat. \#: S271, Fisher Scientific,) and deionized water.

\subsubsection{Regrowth on Recycled Media}

A batch of media was recycled through four rounds of regrowth to test the effects of water recycling on algal growth (Figure 4).

Terms used in the following sections are defined as follows:

Control Conditions: Algae cultivated on fresh media as described in Section 3.6.1.1.

Experimental Variable Conditions: Algae cultivated on recycled water or modified BG11 media with elevated salinity. Growth rates obtained from experimental conditions were compared to those of simultaneous control cultures.

Salinity Experiment Cultures: Refers to the algae cultivated on modified BG11 media with elevated salt content. 


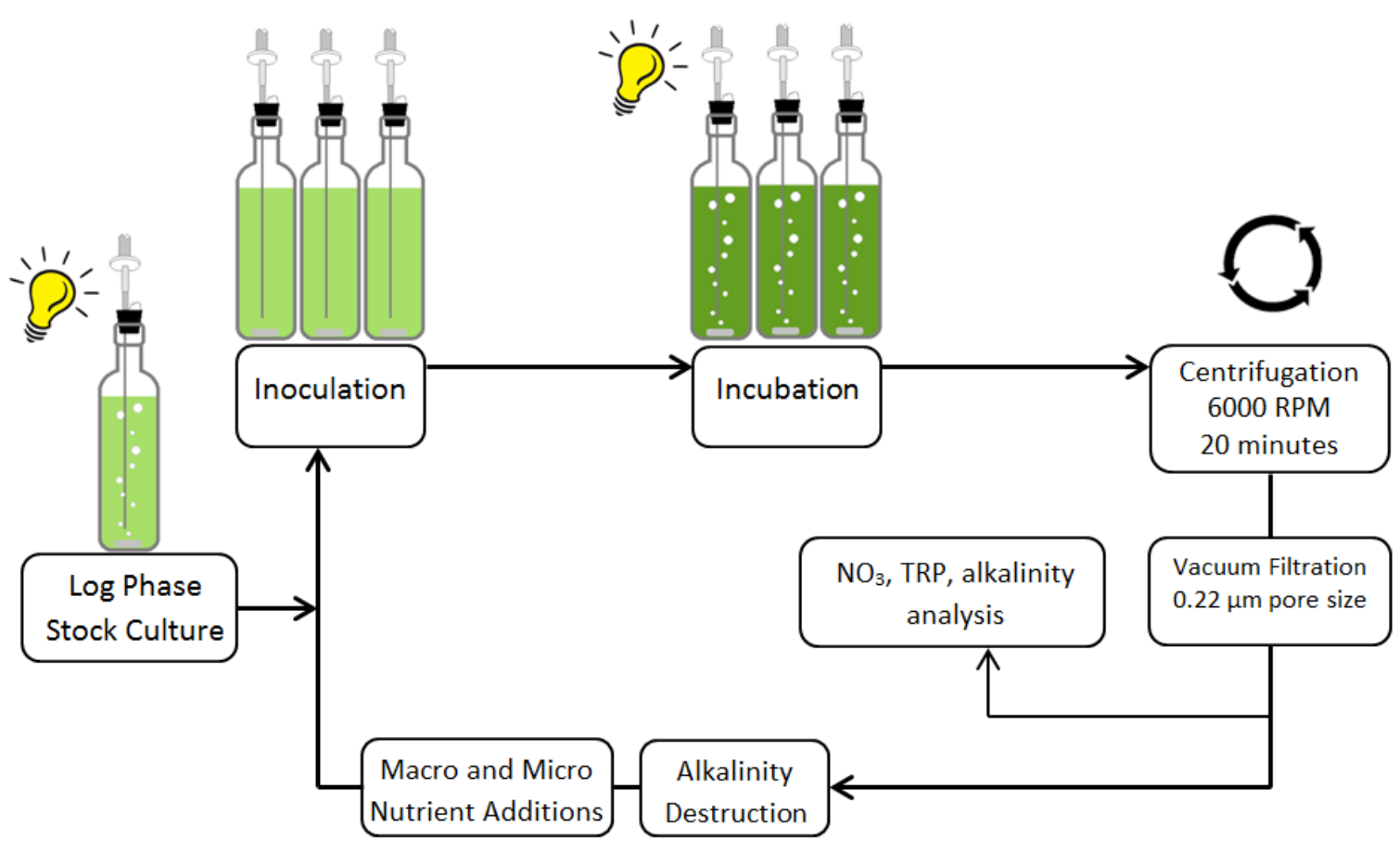

Figure 4: Process flow diagram of the step-by-step procedure used to recycle media through multiple rounds of algae cultivation.

Each control and experimental variable conditions were inoculated from a single stock culture of DOE1412 to a density of $0.06 \mathrm{OD}_{750 \mathrm{~nm}}$ at the beginning of each round of regrowth. Media was recycled a total of four times throughout the course of this research, completing a total of 5 cycles of cultivation and harvesting on a single batch of water. Replicates of each experimental variable condition were incubated during each round of cultivation. These replicates were paired with control conditions located in positions directly across the center baffle on the growth apparatus to minimize the effect of potential biases of stir stations in the growth apparatus.

Volume losses occurred between each round of regrowth due to sample collection for media and biomass analysis and centrifugation and filtration steps. The volume losses required a reduction 
in the number of replicates with each consecutive round of regrowth. The number of experimental and control replicates used in each Round of growth is described in Table 2.

Table 2: The round of growth, number of experimental replicate cultures grown on recycled media, the number of control replicate cultures grown on fresh modified BG11 media, and the degree to which the used media had been recycled.

\begin{tabular}{ccc}
\hline Round & n (Control) & n (Experimental) \\
\hline 1 & 20 & 0 \\
\hline 2 & 10 & 10 \\
\hline 3 & 7 & 7 \\
\hline 4 & 5 & 5 \\
\hline 5 & 4 & 4 \\
\hline Salinity Experiment & 4 & 4 \\
\hline
\end{tabular}

Experimental cultures were only compared to control cultures grown within the same round of regrowth. With the exception of Round 5, all cultures of DOE1412 were incubated until the late linear-phase before removing from the culturing apparatus and storing in a refrigerator at $4{ }^{\circ} \mathrm{C}$ until further processing.

The number of replicates used in the salinity experiment was kept equal to the number used in Round-5 of regrowth. Using an equivalent number of replicates meant the salinity experiment was subject to the same statistical bounds as Round-5, allowing for results to be directly comparable. 


\subsection{Potential Inhibitor Analysis \& Identification}

The following sections describe how potential inhibitory materials present in recycled media were analyzed.

\subsubsection{Carbohydrate Analysis}

The total carbohydrates content of the used media from Round 1-5 per (Van Wychen, and Laurens, 2015).

\subsubsection{Fatty Acid Isolation \& Identification}

The lipid content of recycled media samples obtained from rounds 1-5 was isolated and analyzed as described in the following sections.

The following methods were developed in part based on previous work competed by Yamada et al (1994).

\subsubsection{Ethyl Acetate Extraction}

Extractions were performed on samples of used media obtained from rounds 1-5 of regrowth. All samples of used media were previously frozen until extractions were performed after all experimental rounds of regrowth were concluded.

Each 100-mL sample of used media was extracted with $30 \mathrm{~mL}$ of ethyl acetate (HPLC grade, . Cat. \# E195, Fisher Science) using a 125-mL separatory funnel (cat. \#: 10-437-10B Fisher Scientific,). Recycled media samples were extracted in two 50-mL aliquots due to volume limitations of the separatory funnel. Ethyl acetate was then washed twice with 30-mL aliquots of a saturated solution of $\mathrm{NaCl}$. Ethyl acetate was dried with additions of solid anhydrous sodium 
sulfate (Cat. \#: S415, Fisher Scientific.) and transferred to de-ashed 40-mL screw-top silica glass vials. Ethyl acetate was then filtered through coarse filter paper (Cat. \#: 09-795G, Fisher Scientific) and stored in a freezer until further processing.

\subsubsection{Evaporation of Ethyl Acetate Extract}

Ethyl acetate solvent was then turbo-evaporated (TurboVap II, Caliper LifeScience, Hopkins, Mass.) in 200-mL evaporator tubes to concentrate potential extracted materials. The turboevaporator was operated manually at $30{ }^{\circ} \mathrm{C}$ until ethyl acetate was evaporated to a final volume of approximately 1-mL. The side walls of the evaporator tubes were periodically rinsed with ethyl acetate during evaporation to minimize losses of extracts due to adsorption on evaporator tube sidewalls. Residual ethyl acetate was transferred to $2.0-\mathrm{mL}$ crimp top silica glass vials (Cat. \#: 5182-0543, Fisher Scientific) and the evaporator tubes were rinsed three times with approximately $0.2 \mathrm{~mL}$ aliquots of ethyl acetate. Ethyl acetate rinses were also transferred to glass vials to be combined with their respective sample. Crimp top glass vials containing the ethyl acetate samples were then crimp-sealed with aluminum caps containing PTFE-lined septa (Cat. \#: 5181-1211, Fisher Scientific). Samples were stored in a freezer before further processing.

Ethyl acetate was then fully evaporated in crimp sealed glass vials using nitrogen gas to isolate extracted materials from the ethyl acetate solvent. Syringe needles were inserted into PTFE membranes of crimp sealed glass vials to provide an inlet and outlet for nitrogen gas flow. Ethyl acetate samples were heated to $30^{\circ} \mathrm{C}$ using a heat block (Cat. \#: 13259-032, Standard Heat Block II, VWR) during evaporation. 


\subsubsection{Transesterification \& GC-MS Analysis}

Residual lipid content isolated from ethyl acetate solvent was transesterefied and analyzed via gas chromatography mass spectroscopy (Van Wychen et al, 2015). All samples were analyzed

for fatty acid methyl esters on a GS-MS system (5975B inert MSD GS-MS, Agilent Technologies, Santa Clara, Calif.) with an HP-5MS (5\% Phenyl)-Methyl Siloxane Capillary Column (30.0 m x $250 \mu \mathrm{m} \times 0.25 \mu \mathrm{m}$ nominal, Cat. \#: 19091S-433. Agilent) and a sample injection volume of $5.0 \mu \mathrm{L}$.

\subsection{Analytical Methods}

The following sections describe the methods used to quantify nutrients, alkalinity, salinity, and metals content of used media.

\subsubsection{Optical Density}

Culture growth was monitored as optical density at a wavelength of $750 \mathrm{~nm}\left(\mathrm{OD}_{750}\right)$ as measured by spectrophotometry (GENESYS 20, Spectronic Instruments, Leeds, UK). During log-phase of growth measurements were made at intervals of 20-60 minutes and during linear-phase of growth once every 2-3 hours. Culture samples with $\mathrm{OD}_{750 \mathrm{~nm}} \geq 0.6$ were diluted with deionized water before final OD measurements, to give readings within the linear response range of 0.04$0.6 \mathrm{OD}_{750}$ determined for the spectrophotometer using a 1-cm path length square plastic cuvette. 


\subsubsection{Macro-nutrient and Alkalinity Measurements}

To prevent nutrient limitations, nutrient concentrations were measured and nutrients restored to modified BG11 levels prior to each new round of regrowth. The following sections describe the methods used for quantifying residual nitrate, dissolved reactive phosphorus (DRP), alkalinity, and metals in used media.

All macro-nutrient measurements were performed (Table 3) on samples collected from used media after filtration (Section 3.5.1).

Table 3: The analytical methods for all nutrient, alkalinity, and AFDW measurements (APHA Standard Methods 1995).

\begin{tabular}{ll}
\hline Constituent & \multicolumn{1}{c}{ Analytical Method } \\
\hline Nitrate & $\begin{array}{l}\text { Nitrate ion selective electrode with interference } \\
\text { suppression solution (APHA Method 4500- } \mathrm{NO}_{3} \text {-D) }\end{array}$ \\
\hline Dissolved reactive phosphorus & $\begin{array}{l}\text { Ascorbic acid, Fisherbrand 0.45- } \mu \text { multiple } \\
\text { cellulose ester filtration (APHA Method 4500-P E) }\end{array}$ \\
\hline Alkalinity & Sulfuric acid titration (APHA Method 2320 B) \\
\hline Ash-free dry weight & $\begin{array}{l}\text { 1.2- } \mu \text { m glass fiber filters (G4, Cat. \#: 09804110A, } \\
\text { Fisher Scientific) (APHA Method 5210 B) }\end{array}$ \\
\hline
\end{tabular}

\subsubsection{Salinity Measurements}

Salinity was measured using a Hach sensION 5 Conductivity meter (Cat. \#: EW1960400, ColeParmer). 


\subsubsection{Metals Analysis}

For used media samples in which metals content was quantified, samples of whole unfiltered culture were preserved with concentrated nitric acid (16 M, trace metal grade) and refrigerated. Samples were analyzed by ICP (EPA Method 200.7) at a commercial laboratory. 


\section{Results and Discussion}

The goals of this research were to investigate the effect of media recycling on the log-phase and linear-phase growth rates of DOE1412 and to identify potential biological inhibitors which may accumulate in recycled media. The following sections discuss the data and results obtained from the characterization of used media, including nutrient, alkalinity, salinity, and metals analysis, the biomass correlation study, and the bioassays of Round 2-5 of cultivation and the salinity experiment.

\subsection{Used Media Characterization}

Residual constituents present in used modified BG11 media were measured at the end of each round of cultivation (Sections 3.5.2).

\subsubsection{Nutrient Levels at End of Cultivation}

The nitrogen and phosphorus concentrations present in used media after cultivation was measured so that residual nutrient concentrations could be compared to that of modified BG11 media (Table 4). These measurements were used to calculate the required doses of $\mathrm{N}$ and $\mathrm{P}$ stock nutrient components needed to restore the $\mathrm{N}$ and $\mathrm{P}$ content of used media to initial concentrations. 
Table 4: Concentration of residual sodium nitrate and dipotassium phosphate measured in used media at the end of each round of growth. Percentages of residual nitrogen and phosphorus were calculated with respect to values in the modified BG11 media recipe. Residual nitrogen and phosphorus ions present in the Round-5 used media and used modified BG11 eith elevated salinity were not measured. Residual nitrate and phosphate ions were measured using procedures cited in section 3.5.2.

\begin{tabular}{ccccc}
\hline Round & $\begin{array}{c}\text { Residual N as } \\
\mathbf{N a N O}_{\mathbf{3}}(\mathbf{m g} / \mathbf{L})\end{array}$ & $\begin{array}{c}\text { Residual N } \\
(\%)\end{array}$ & $\begin{array}{c}\text { Residual P as } \\
\mathbf{K}_{\mathbf{2}} \mathbf{H P O} \\
(\mathbf{m g} / \mathbf{L})\end{array}$ & $\begin{array}{c}\text { Residual P } \\
(\%)\end{array}$ \\
\hline 1 & 173 & 11.6 & 0.589 & 1.47 \\
\hline 2 & 1159 & 77.2 & 1.11 & 2.76 \\
\hline 3 & 1589 & 105 & 2.32 & 97.4 \\
\hline
\end{tabular}

\subsubsection{Alkalinity Measurements at End of Cultivation}

The alkalinity of used media was measured at the end of Rounds 1 and 3 of growth (Table 5).

The alkalinity of used media obtained after Rounds 2, 4, and 5 as well as that of modified BG11 with elevated salinity at end of cultivation, was not measured. The alkalinity of used media increased substantially after each round cultivation. 
Table 5: Alkalinity of Round-1 and Round-3 used media. These measurements were compared to measurements obtained from freshly prepared modified BG11 media taken at time of analysis to assess the excess amount of alkalinity produced during cultivation. All value are represented as $\mathrm{CaCO}_{3}$ equivalents.

\begin{tabular}{ccc} 
Round & $\begin{array}{c}\text { Alkalinity of used } \\
\text { media (mg/L) }\end{array}$ & $\begin{array}{c}\text { Alkalinity of modified } \\
\text { BG11 media (mg/L) }\end{array}$ \\
\hline 3 & 434 & 26.8 \\
& 408 & 29.6
\end{tabular}

\subsubsection{Salinity Measurements at End of Cultivation}

Salinity increased significantly with each round of growth up to $6.4 \mathrm{mS} / \mathrm{cm}$ in recycled water (Table 6). 
Table 6: Salinity of recycled media with replenished nutrients, modified BG11 media, and modified BG11 media with elevated salinity.

Media

Modified BG11 medium

Round-2 recycled medium

Round-3 recycled medium

Round-4 recycled medium

Round-5 recycled medium

Modified BG11 media with elevated salinity

\section{Salinity (mS/cm)}

1.6

3.8

5.0

5.4

6.4

6.4

\subsubsection{Metals Concentrations}

Cobalt, copper, and iron were completely depleted from the Round 4 growth medium, while concentrations of Mo, $\mathrm{Zn}, \mathrm{Ca}, \mathrm{Mg}, \mathrm{K}$, and $\mathrm{Na}$ increased substantially (Table 7). 
Table 7: Residual metals content of Round-4 used media and the corresponding concentration present in modified BG11 media. The accumulation is calculated as a percentage in respect to modified BG11 media.

\begin{tabular}{lccc}
\hline Constituent & \multicolumn{2}{c}{ Concentration (mg/L) } & \\
\cline { 2 - 3 } & $\begin{array}{c}\text { Round-4 used } \\
\text { media }\end{array}$ & $\begin{array}{c}\text { Modified BG11 } \\
\text { media }\end{array}$ & Accumulation (\%) \\
\hline Cobalt & Not Detected & 10 & $100 \%$ Depleted \\
Copper & 0.462 & 20 & $100 \%$ Depleted \\
Molybdenum & 0.245 & 0.16 & 298 \\
Zinc & 4.19 & 0.05 & 490 \\
Phosphorus & 33.8 & 5.4 & $23 \%$ Depleted \\
Calcium & Notected & 9.8 & 344 \\
Iron & Detected & 1.2 & NA \\
Magnesium & 23.8 & 7.4 & 322 \\
Manganese & 1.49 & 0.50 & 297 \\
Potassium & 41.1 & 0.35 & 11,000 \\
Sodium & 1020 & 406 & 251 \\
\hline
\end{tabular}

A substantial accumulation of various metal constituents would be expected in the Round-4 medium. The concentration of residual zinc in the Round-4 used medium was $0.245 \mathrm{mg} / \mathrm{L}$, or $490 \%$ of the concentration present in modified BG11 media. Using the elemental composition of Chlorella vulgaris (Mandalam, 1998), it was found that this accumulation of zinc should not have occurred based on the total biomass yield of DOE1412 at the end of Round 1-5 of growth. This suggests that DOE1412 consumed significantly less Zinc than anticipated which led to the accumulation over multiple rounds of media recycling. Zinc is known to be toxic to Chlorella sp. Literature values for the $\mathrm{EC}_{50}$ of zinc measured for a fresh water species of Chlorella ranged from 0.09 mg/L (Franklin, 2002), $5.1 \mathrm{mg} / \mathrm{L}$ (Rosko, 1977), and $12 \mathrm{mg} / \mathrm{L}$ (Rai, 1981). It is possible that the accumulation of zinc is the cause of the inhibition observed in Rounds 2-5 of 
regrowth. However, it is uncertain if the concentration of zinc present in Round-4 media had an effect on the growth of DOE1412.

Manganese accumulated in Round-4 used media to $297 \%$ of the concentration present in modified BG11 media. A literature $\mathrm{EC}_{50}$ found for a salt water green algae, Chlorella stigmatophora, was measured at $50 \mathrm{mg} / \mathrm{L}$ which is substantially higher than the concentration of manganese measured in Round-4 used media (Christensen, 1979). No other literature data for manganese toxicity was obtained for other species of Chlorella. A literature $\mathrm{EC}_{50}$ for a fresh water green algae, Selenastrum capricornutum, was measured at $3.1 \mathrm{mg} / \mathrm{L}$ (Christensen, 1979). It is possible that the accumulation of manganese affected the growth of DOE1412 given that the concentration of manganese in the Round-4 media is near to the $\mathrm{EC}_{50}$ value cited for Selenastrum capriconutum. However, there is not sufficient information to support such a conclusion.

While a significant accumulation of molybdenum did occur in the Round-4 used media, no molybdenum toxicity data for green algae was found in literature. While it is possible molybdenum affected the growth of DOE1412, more data is needed to show that molybdenum can be toxic at concentrations present in the Round-4 media.

\subsection{Biomass Correlation}

A plot of $\mathrm{OD}_{750}$ vs AFDW is given in Figure 5. VSS measurements collected in triplicate which did not have a relative standard deviation of less than $5 \%$ were not used. 


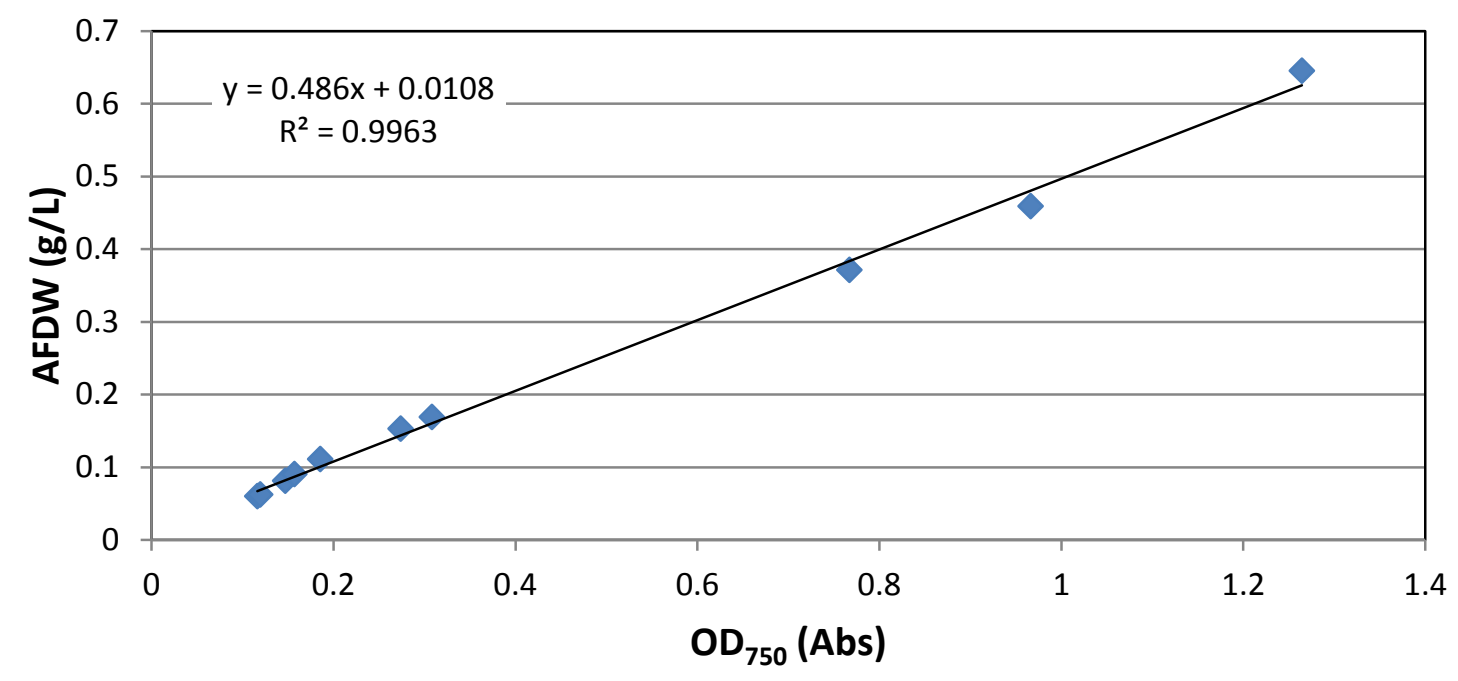

Figure 5: Correlation of $\mathrm{OD}_{750}$ vs AFDW for Chlorella sorokiniana.

The AFDW was found to be linearly correlated with $\mathrm{OD}_{750}\left(\mathrm{r}^{2}=0.996\right)$. The linear relationship is provided in Equation 5.

$$
A F D W=0.486 \frac{g}{A b s \cdot L}\left[O D_{750 n m}\right]
$$

\subsection{Growth Curves}

Growth curves were plotted as $\mathrm{OD}_{750}$ and the natural $\log$ function of $\mathrm{OD}_{750}\left(\operatorname{lnOD}_{750}\right)$ against time in days on separate axes (Figure 6). 


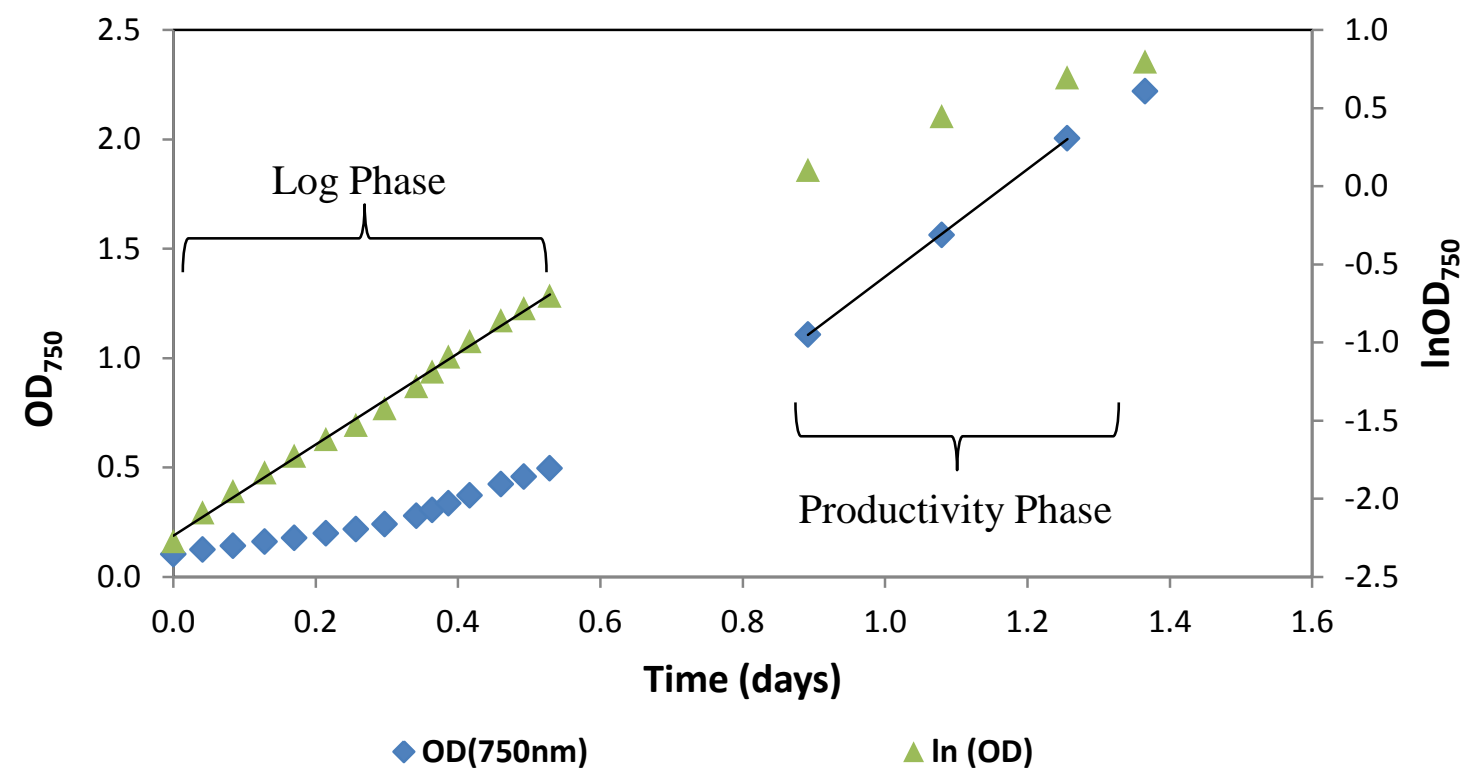

Figure 6: Example growth curve. The logarithmic growth phase was characterized by a linear trend in the $\operatorname{lnOD}_{750}$ plot while the productivity phase was characterized by a linear trend in the $\mathrm{OD}_{750}$ plot. This particular growth curve was obtained from replicate Control-1 of Round-5 of regrowth.

Log-phase and linear-phase growth rates were obtained from the slopes of the observed log and productivity phases of growth, respectively, using linear regression.

\subsection{Log-phase Growth Rates}

Log-phase growth rates were obtained from each round of regrowth on recycled water and growth on modified BG11 media and with elevated salinity (Figure 7). 


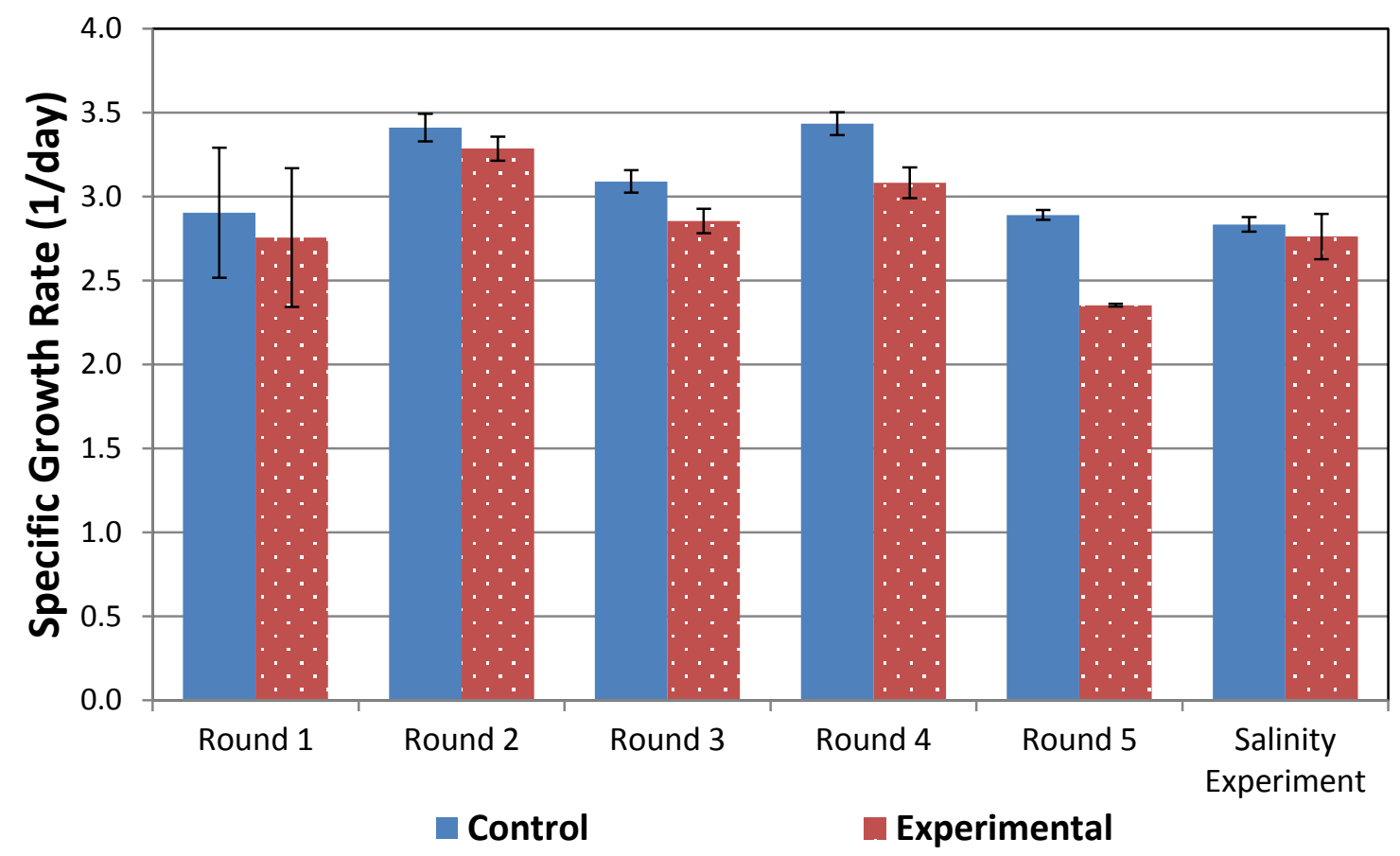

Figure 7: Specific growth rates obtained for control and experimental conditions from Rounds 1-5 of regrowth and the salinity experiment. Error bars indicate mean $+/-$ the sample standard deviation of specific growth rate.

A high amount of variability (13-15\% relative standard deviation) was observed in specific growth rates obtained from Round-1 when compared to Rounds 2-5 (0.3-3\% relative standard deviation). This variability was caused by temperature variation between growth vessels during cultivation due to non-uniform heating by the ballasts of the fluorescent light fixtures. To alleviate this effect, the temperature equilibrating circulated water bath (Section 3.1) was installed to stabilize temperature before continuing with Round-2 of regrowth.

The specific growth rates obtained from Round 2-5 had exceptionally low variability. This low variability was achieved by using a high degree of consistency and control throughout 
experimentation. Alkalinity, nutrient loading, temperature, light intensity, and $\mathrm{pH}$ were kept constant within each set of conditions while $\mathrm{OD}_{750}$ measurements were collected at constant time intervals across all replicate cultures. These practices led to consistent culturing conditions across all replicate cultures which yielded exceptionally consistent specific growth rates. The low variability in specific growth rates significantly lowered the detection limit required to observe inhibition.

Log-phase growth rates of control cultures across all rounds of growth ranged from 2.8-3.4 day ${ }^{-1}$. The variation of log-phase growth rates between rounds of growth was not correlated with temperature or $\mathrm{pH}$. It is possible that this variation was due to the condition of the inoculum used to seed cultures at the start of each round of growth. The log-phase growth rates of recycled media cultures fell with each consecutive round of regrowth on recycled media. 


\subsection{Productivity Growth Rates}

Productivity growth rates were obtained from round 5 of regrowth and the salinity experiment

(Figure 8). These values were obtained using methods described in section 3.4.

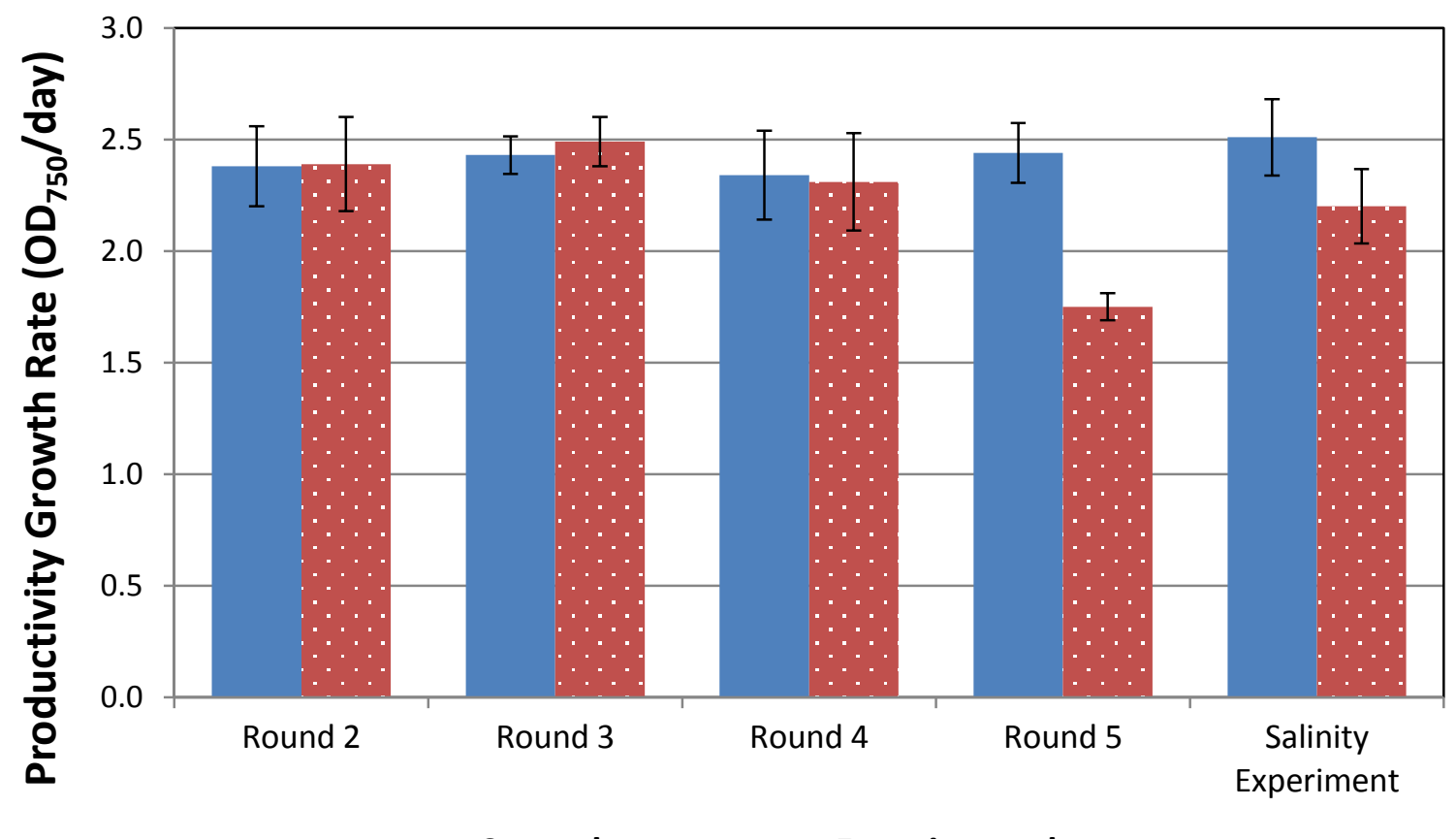

Control Experimental

Figure 8: Productivity growth rates obtained from Round 2-5 of regrowth and the salinity experiment. Error bars indicate mean $+/$ - standard deviation of productivity growth rate.

The Round 5 and elevated salinity conditions each had their own set of control cultures which consisted of algae grown on fresh media. For Rounds 2-4, linear-phase growth rates were similar to controls grown in fresh media, indicating no inhibition of growth from using recycled media. However, while the linear-phase growth rates for the sets of controls used in both the Round 5 
and elevated salinity experiment exhibited similar linear-phase growth rates, Round 5 and elevated salinity cultures exhibited linear-phase growth rates lower than control culture. The productivity growth rates of Round-5 media were also significantly lower than those of the elevated salinity conditions.

\subsection{Observed Inhibition}

The following sections describe all instances of growth inhibition observed throughout the course of this research.

\subsubsection{Percent Inhibition}

Inhibition was quantified as the difference between specific or productivity growth rates in control and experimental cultures. Inhibition was calculated as a percentage using Equation 6.

$$
\operatorname{Inhibition}(\%)=100 \% \cdot\left(1-\frac{r_{e}}{r_{c}}\right)
$$

where $r_{e}$ is the mean growth rate of replicate experimental cultures (e.g., recycled water or elevated salinity) and $r_{c}$ is the mean growth rate of the replicate paired control cultures.

The calculated percent inhibition for specific growth rates is provided for all rounds of regrowth on recycled water and the elevated salinity experiment in Figure 9. Inhibition during log-phase growth increased steadily with each round of media recycling. 


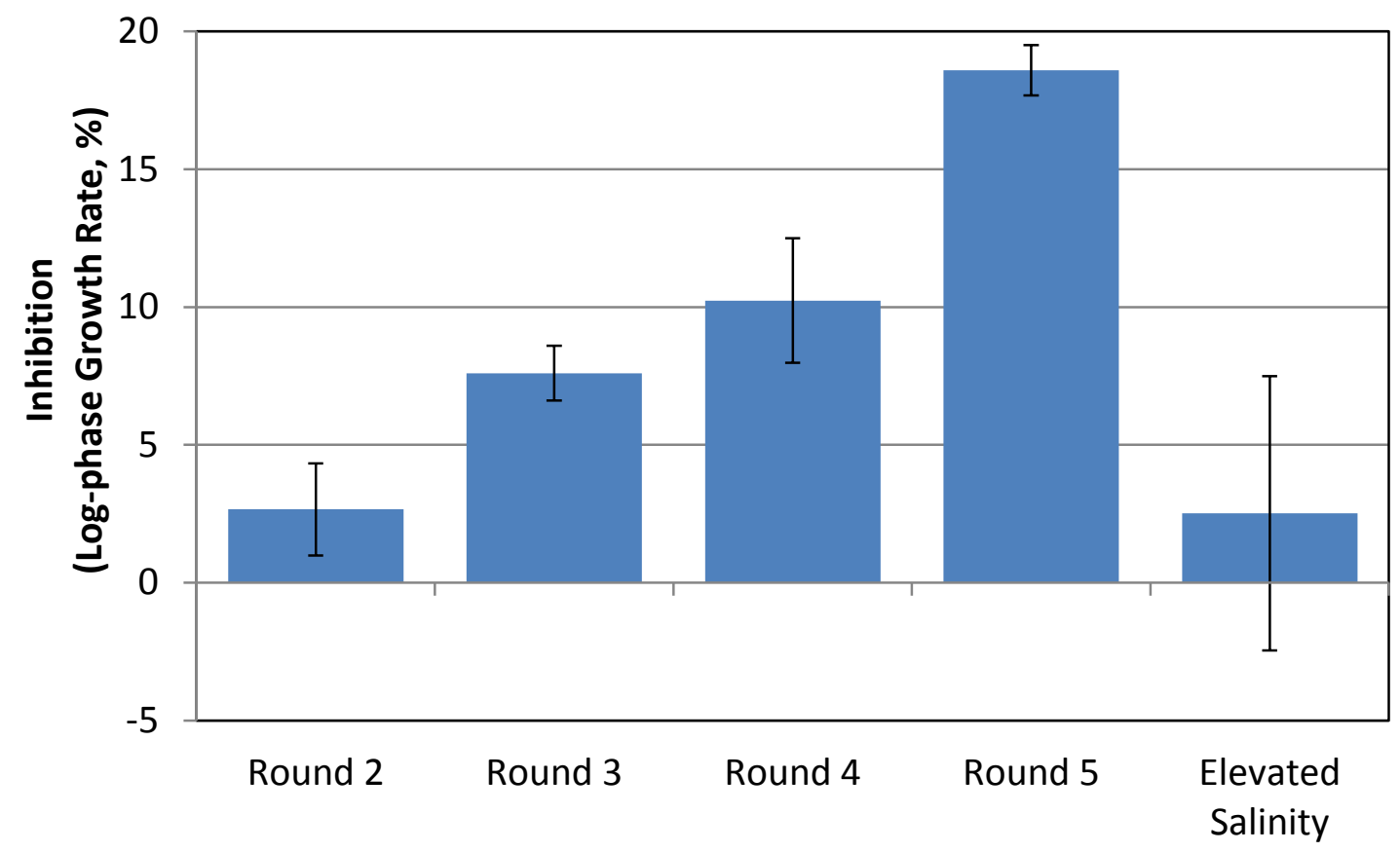

Figure 9: Percent inhibition of log-phase growth rates obtained from Rounds 1-5 of regrowth and the salinity experiment. Error bars represent the sample standard deviation of percent inhibition in both the positive and negative directions.

The calculated percent inhibition observed in productivity growth rates is provided for Round-5 of regrowth on recycled water and the salinity experiment in Figure 10. No inhibition was observed in linear-phase growth rates of Rounds 2-4. The linear phase growth rate of Round 5 and the elevated salinity experiment was $28 \%$ and $13 \%$, respectively. 


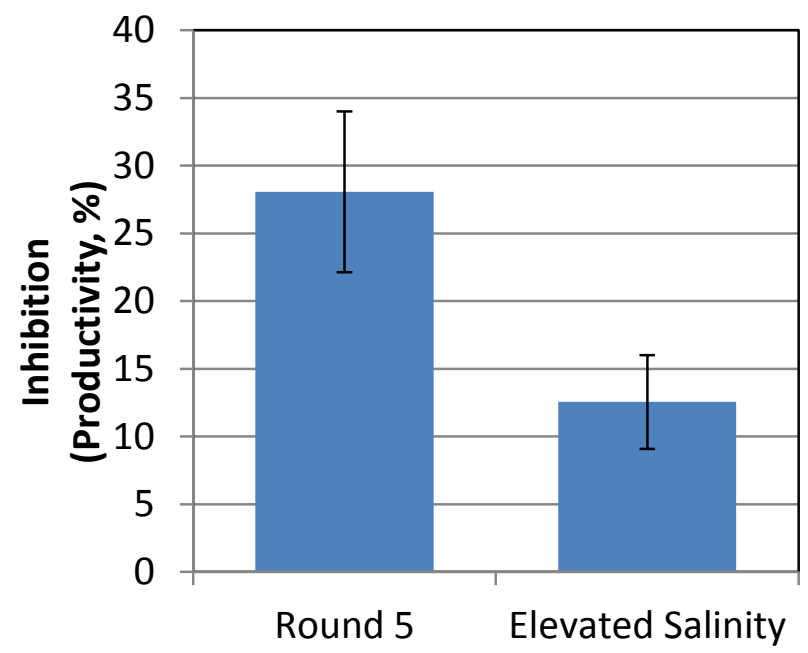

Figure 10: Percent inhibition of productivity in Round-5 of regrowth and the elevated salinity experiment. Error bars represent the sample standard deviation in the positive and negative directions.

The observed differences in log-phase growth rates between controls and recycled water was statistically significant in all rounds of regrowth at a $99 \%$ confidence level. However, the observed difference in log-phase growth rates between experimental controls and elevated salinity conditions was statistically significant at a confidence level of $80 \%$, which does not satisfy the criteria needed to conclude inhibition was observed. These results show that the accumulation of salts in recycled media did not significantly affect specific growth rates.

Conversely, Round-5 recycled media and modified BG11 media with elevated salinity did have significant effect on productivity growth rates (99\% confidence level). However, the observed inhibition in elevated salinity conditions was not as high as that of Round-5 conditions. While salinity did have an appreciable effect on productivity growth rates, the accumulation of salts may not fully explain the degree of inhibition observed in Round-5. 
The percent inhibition, calculated t-value, critical value, as well as the corresponding confidence interval are tabulated in Table 9.

Table 8: Percent inhibition, degrees of freedom, calculated t-value, critical t-value, and respective confidence interval for all specific and productivity growth rates obtained from Rounds 2-5 of regrowth on recycled water and the elevated salinity experiment.

\begin{tabular}{|c|c|c|c|c|c|}
\hline Experiment & $\begin{array}{c}\text { Inhibition } \\
(\%)\end{array}$ & $\begin{array}{c}\text { Degrees of } \\
\text { Freedom }\end{array}$ & $\mathbf{t}_{\text {exp }}$ & $\mathbf{t}_{\text {crit }}$ & $\begin{array}{c}\text { Confidence } \\
\text { Level }\end{array}$ \\
\hline \multicolumn{6}{|c|}{ Specific Growth Rates } \\
\hline Round 2 & $3 \pm 2$ & 9 & 4.95 & 2.82 & \multirow{4}{*}{$>0.99$} \\
\hline Round 3 & $8 \pm 1$ & 6 & 20.52 & 3.14 & \\
\hline Round 4 & $10 \pm 2$ & 4 & 10.05 & 3.75 & \\
\hline Round 5 & $18.6 \pm 0.9$ & 3 & 34.29 & 4.54 & \\
\hline $\begin{array}{c}\text { Elevated } \\
\text { Salinity }\end{array}$ & $3 \pm 5$ & 3 & 1.02 & 0.978 & $>0.80$ \\
\hline \multicolumn{6}{|c|}{ Productivity Growth Rates } \\
\hline Round 2 & $0 \pm 8$ & 9 & 0.04 & 0 & 0.50 \\
\hline Round 3 & $-2 \pm 4$ & 6 & 1.4 & 0 & 0.50 \\
\hline Round 4 & $1 \pm 4$ & 4 & 0.9 & 0.741 & $>0.75$ \\
\hline Round 5 & $28 \pm 6$ & 3 & 7.5 & \multirow[b]{2}{*}{4.54} & \multirow[b]{2}{*}{$>0.99$} \\
\hline $\begin{array}{c}\text { Elevated } \\
\text { Salinity }\end{array}$ & $13 \pm 3$ & 3 & 6.53 & & \\
\hline
\end{tabular}

The log-phase growth rate was inhibited in each round of regrowth on recycled water.

Furthermore, inhibition during log-phase increased with every consecutive round of regrowth, suggesting that water recycling does have a negative cumulative effect on algal growth during log-phase. Given that nutrients were replenished before each round of regrowth, these effects 
cannot be explained by nutrient limitations. Alkalinity, $\mathrm{pH}$, and temperature were also controlled, and therefore did not have a significant influence on specific growth rates. Salt accumulation was also tested and did not have an appreciable effect when compared to experimental controls.

The productivity growth rates observed in Round-5 and in the elevated salinity experiment were significantly inhibited while productivity growth rates observed in Rounds 2-4 were not. However, the productivity growth rates of the high salinity conditions were not inhibited to the same extent as those of Round-5 cultures. It is unlikely that salt accumulation can explain the inhibition observed in Round-5 productivity growth rates but the salinity content of the Round-5 medium may have partially contributed to the observed inhibition.

These results suggest that water recycling may lead to an accumulation of inhibitory substances. Based on these results, it is unclear if the observed inhibition is due to an accumulation of biological inhibitors or some other non-biological constituent not accounted for in this research.

\subsection{Analysis of Potential Exudates}

An effort was made to shed light on why recycled media inhibited the growth of DOE1412. Carbohydrate content of used media was analyzed to assess the amount of fixed carbon shed by DOE1412 during cultivation. This analysis was useful for gauging the amount of exuded organic materials produced by DOE1412 during growth which may serve as an indicator for the presence of inhibitory compounds. The PUFA content of used media was also analyzed, given the evidence of their inhibitory nature. Together, these two efforts were undertaken to provide insight into the potential for growth inhibitor accumulation in recycled media. 


\subsubsection{Carbohydrates Analysis}

The soluble carbohydrate content of used media was of interest as a means of qualitatively evaluating the accumulation of organic materials caused by water recycling. The carbohydrate content of used media obtained from Round 1-5 of (Figure 11). Hydrolyzed denotes carbohydrates detected as polysaccharides while non-hydrolyzed denotes carbohydrates detected as simple monomeric sugars.

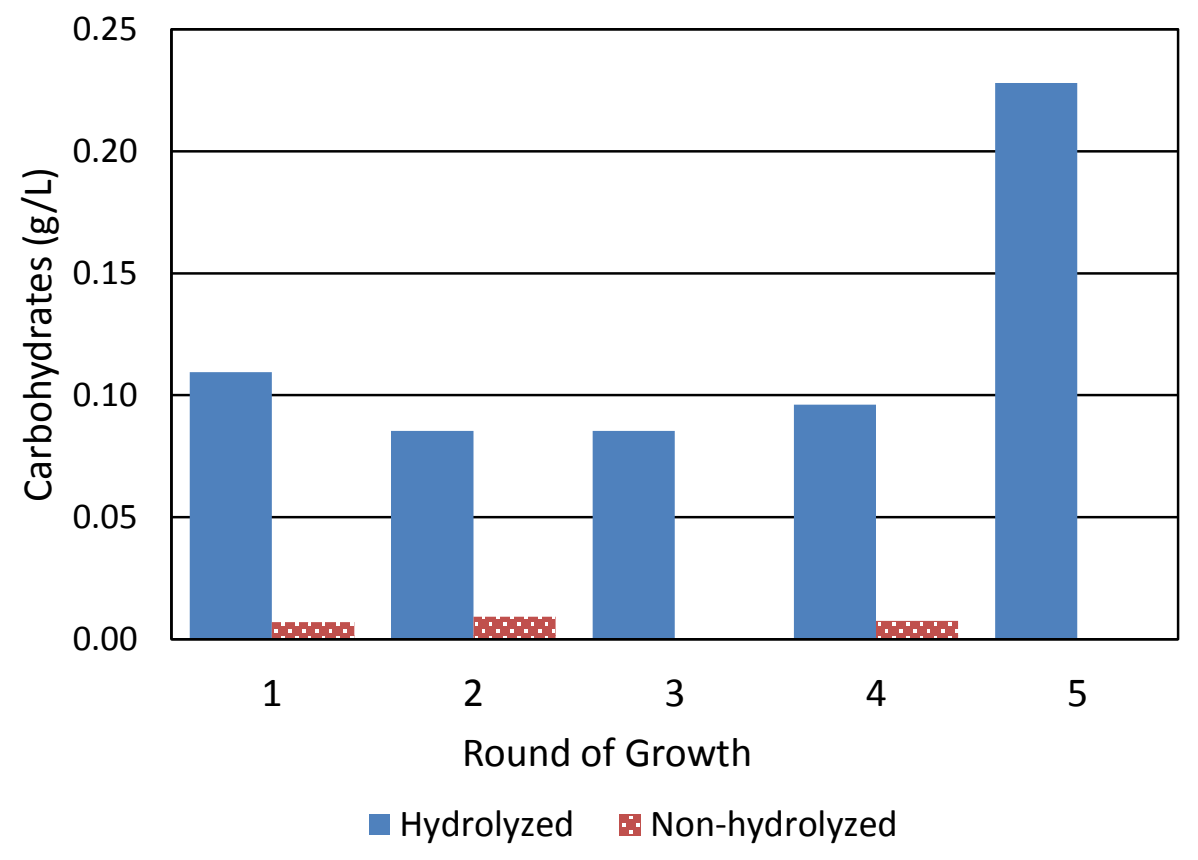

Figure 11: Hydrolyzed and non-hydrolyzed carbohydrate content of used media.

The carbohydrate content of used media was largely present as soluble polysaccharides, characterized by the high hydrolyzed carbohydrate content measured compared to the non- 
hydrolyzed content which represents simple sugars. However, the carbohydrate content of used media did not increase in Rounds 1-4 but remained relatively stable, which may be due to heterotrophic metabolism of solubilized polysaccharides by bacteria or the algae themselves during cultivation. A sharp increase in carbohydrate content is observed in Round-5 used media, likely due to Round-4 cultures having been frozen without removing algae biomass. Frozen Round-4 cultures likely experienced multiple freeze-thaw cycles during storage due to inadequate temperature control, potentially causing some algae biomass to lyse and release cellular contents into solution, including polysaccharides.

While carbohydrates were present in significant amounts throughout Round 2-4 of recycling, carbohydrates did not accumulate until Round-5. Given that log-phase inhibition increased with each round of recycling and carbohydrate concentration did not, carbohydrates are not the likely source of inhibition. However, the soluble carbohydrate content indicated how much fixed organic carbon was released by the algae or associated bacteria during growth. For Round 1-4, 8 to 10 percent of fixed carbon was released as carbohydrates while this figure jumped to 18 percent for Round 5, presumably due to the freeze-thaw cycles this media experienced during storage. Ignoring the increased carbohydrate content of Round 5 used media, the stability of the carbohydrate content does not necessarily rule out an accumulation of some organic materials. Carbohydrates are readily metabolized by both algae and bacteria whereas this may not be true with other organic compounds, some of which may be inhibitory. If such inhibitory compounds are not metabolized, then it's possible for said compounds to accumulate with each round of regrowth. 


\subsubsection{Fatty Acid Isolation \& Identification}

No FAMEs were detected in samples prepared from used media obtained from Rounds 1-4.

However, significant amounts of FAMEs were detected in samples prepared from Round-5 used media (Table 10). Concentrations of all PUFAs detected were estimated using an internal tridecanoic acid methyl ester internal standard. This method is not rigorous but gives a rough estimate of concentrations.

Table 9: FAMEs detected in Round-5 used media and their respective correlations and estimated concentrations. The correlation percentage represents the degree that the mass-spectrometer signal for each substance below matches the respective database signal. Commons names are provided in parenthesis for each substance when available.

\begin{tabular}{|c|c|c|}
\hline Species & Confidence & $\begin{array}{c}\text { Estimated Concentration } \\
\text { in Round-5 used media } \\
(\mu \mathrm{g} / \mathrm{L})\end{array}$ \\
\hline $\begin{array}{l}\text { 7,10-Hexadecdienoic acid methyl } \\
\text { ester }\end{array}$ & $39.6 \%$ & 0.6 \\
\hline $\begin{array}{l}\text { 7,10,13-Hexadecatrienoic acid } \\
\text { methyl ester }\end{array}$ & $52.0 \%$ & 0.16 \\
\hline Hexadecanoic acid methyl ester & $79.2 \%$ & 0.07 \\
\hline $\begin{array}{c}\text { 9,12-Octadecadienoic acid methyl } \\
\text { ester }\end{array}$ & $77.9 \%$ & 0.1 \\
\hline $\begin{array}{l}\text { 9,12,15-Octadecatrienoic acid } \\
\text { methyl ester }\end{array}$ & $76.1 \%$ & 0.5 \\
\hline Octadecanoic acid methyl ester & $90.2 \%$ & 0.3 \\
\hline
\end{tabular}


Polyunsaturated fatty acids (PUFAs) have been shown to inhibit algal growth, specifically linoleic and linolenic acid and their degradation byproducts (Ikawa, 1997). Linoleic and linolenic acids were detected in significant quantities in the Round-5 used media (Section 4.8). However, these PUFAs were not detected in the Round 1-4 used media.

It is possible that these substances were introduced into solution by cell lysis caused by the freeze-thaw cycles of Round-4 used media as described in Section 4.7. While freezing samples of whole biomass is an approved method for preserving samples destined for both carbohydrate and FAMEs analysis (Van Wychen, and Laurens, 2015. Appendix B)(Van Wychen et al, 2015. Appendix C), such methods are designed to analyze algae biomass whereas this research aimed to characterize extracellular materials produced during algae cultivation and not algae biomass, thus potential cell lysage in the Round-4 used media is an important consideration when interpreting these results. Biomass in Round-4 used media should have been removed before freezing. Instead, whole culture was frozen and stored. For Round 1-4, used media was frozen with biomass removed for long-term preservation spanning from weeks to months.

Whether these substances had an appreciable effect on the observed inhibition in Round 5 of regrowth is uncertain. The inhibitory concentration threshold of linoleic and linolenic acid for Chlorella pyrenoidosa was measured at $0.5 \mathrm{mg} / \mathrm{L}$ (Ikawa, 1997). Given that the concentrations estimated in this study were far below this threshold, it is unlikely these substances had an appreciable effect. Furthermore, these constituents were not detected in used media obtained 
from Round 1-4 so it is unlikely that they had an effect on the inhibition observed in log-phase rates throughout cultivation. It is possible that the detected PUFAs affected linear-phase growth rates. However, whether these substances were present in Round 5 recycled water is uncertain, therefor no meaningful conclusions can be drawn from the results of this study. 


\section{Conclusions}

The growth rate of DOE1412 was affected by recycled media through multiple round of regrowth. During log-phase growth the initial growth rate decreased steadily by $4 \pm 3 \%$ for each round, but for linear-phase growth inhibition was only observed in the last round of regrowth. Media recycling may thus detrimentally impact the cultivation of DOE1412 and therefore increase the cost and land area needed for scaled-up biofuel production.

This research shows that cultivation of DOE1412 on recycled media does lead to the build-up of measurable amounts of organic material during cultivation, some of which may be inhibitory in nature. It is possible that the observed inhibition was caused by an accumulation of some inhibitory compound in recycled media exuded by the algae or associated bacteria during cultivation. Furthermore, PUFAs which have been previously shown to be auto-inhibitory in nature were identified in the Round 5 media, thus we have confirmed that DOE1412 does produce inhibitory compounds. However, whether DOE1412 exudes such compounds during cultivation in significant amounts remains uncertain.

The accumulation of zinc, manganese, and molybdenum was observed in recycled media which also may have caused the inhibition observed in log-phase of growth. This accumulation of metals could be avoided in future experiments by not adding additional zinc after each round of regrowth. Due to the aforementioned confounding factors, further work is needed to determine if recycling media during the cultivation of DOE1412 will lead to an accumulation of growth inhibiting compounds exuded by the algae. 
While here we showed that recycled media had an appreciable effect on the growth of DOE1412, later experiments involving media and nutrient recycling in the semi-cultivation of polycultures of algae yielded no observable inhibition. Given that open-pond systems commonly employ the use of polycultures maintained continuously in linear-phase of growth, these later experiments were more indicative of the utility of media and nutrient recycling for such systems. 


\section{Future Work}

The following sections describe suggested changes to the above method and further studies needed to obtain robust conclusions from the results of this research.

\subsection{Zinc Toxicity Study}

Zinc toxicity in algae varies between species (Monteiro, 2011). Given the significant accumulation of zinc observed in this study, the toxicity of zinc and other metals to DOE1412 should be investigated. A simple growth experiment, similar in design to the elevated salinity experiment described in this research, would elucidate the effects of zinc on specific and productivity growth rates of DOE1412.

Alternatively, zinc accumulation would need to be monitored throughout water recycling experiments to prevent accumulation, nullifying the need for a zinc toxicity test. Ideally, all macro and micro nutrients would be monitored throughout each round of regrowth on recycled water to prevent accumulations of potentially toxic substances derived from media inputs. Such accumulations act as confounding factors which would undermine any potential conclusions drawn. 


\subsection{Inhibitor Identification}

To conclusively show that the inhibition observed in this research is due to auto-inhibitory or allelopathic substances, potential inhibitors would need to be extracted from used media and identified. Furthermore, potential inhibitors would need to be evaluated for inhibitory effects. This could be accomplished by isolating and concentrating suspected inhibitors and dosing said substances into algal cultures to evaluate their effects on growth at various concentrations. Alternatively, a paper disk assay procedure may be performed as described by Ikawa et al, 1997. 


\section{REFERENCES}

Christensen, E. Scherfig, J. Effects of Manganese, Copper, and Lead on Selenastrum capricornutum and Chlorella stigmatophora. Water Research 13 (1979) 79-92

Davis, R. Aden, A. Pienkos, P. Techno-economic analysis of autotrophic algae Fuel Production. Applied Energy 88 (2011) 3524-3531

Fergola, P. Cerasuolo, A. Polio, G. Pinto, M. DellaGreca. Allelopathy and competition between Chlorella vulgaris and Pseudokirchneriella subcapitata: Experiments and mathematical model. Ecological modeling 208 (2007) 205-214

Franklin, NM. Stauber, JL. Lim, RP. Petocz, P. Toxicity of Metal Mixtures to a Tropical Freshwater Alga (Chlorella sp.): The Effect of Interactions between Copper, Cadmium, and Zinc on Metal Cell Binding and Uptake. Environmental Toxicology Chemistry. 11 (2002) 2412-2422

Harris, D. Growth Inhibitors Produced by the Green Algae (Volvocaceae). Arch. Mikrobiologie. 76 (1971) $47-50$

Hirao, S. Tara, K. Kuwano, K. Tanaka, J. Ishibashi, F. Algicidal Activity of Glyercolipids from Brown Alga Ishige sinicola toward Red Tide Microalgae. Bioscience Biotechnology Biochemistry 76 (2012) 372-374

Ikawa, M. Sasner, J. Haney, J. Inhibition of Chlorella growth by degredation and related products of linoleic and linolenic acids and the possible significance of polyunsaturated fatty acids in phytoplankton ecology. Hydrobiologia 356 (1997) 143-148

Kakisawa, H. Asari, F. Kusumi, K. Toma, T. Sakurai, S. Oohusa, T. Hara, Y. Chiharai, M. An Allelopathic Fatty Acid from the Brown Alga Cladosiphon okamuranus. Phyotchemistry 27 (1988) 731-735.

Lardon, L. Helias, A. Sialve, B. Steyer, J. Bernard, O. Life-Cycle Assessment of Biodiesel Production from Microalgae. Environmental Science \& Technology 43 (2009) 6475-6481

Legrand, C. Rengefors, K. Fistarol, G. Graneli, E. Alleolpathy in Phytoplanton - Biochemical, Ecological, and Evolutionary Aspects. Phycologia 42 (2003) 406-419 
Medipally, S. Yusoff, F. Banerjee, S. Shariff, M. Microalgae as Sustainable Renewable Energy Feedstock for Biofuel Production 2015 (2015) Article ID 519513

Monteiro, C. Fonseca, S. Castro, P. Malcata, F. Toxicity of cadmium and zinc on two microalgae, Scenedesmus obliquss and Desmodesmus pleimorphus, from Northern Portugal 23 (2011) 97-103

National Alliance For Advanced Biofuels and Bioproducts (NAABB) Final Report (2014). Retrieved May 18, 2016 from http://www.energy.gov/sites/prod/files/2014/07/f18/naabb_full_final_report_section_II_0 .pdf

Rai, L. Gaur, J. Kumar, H. Protective Effects of Certain Environmental Factors on the Toxicity of Zinc, Mercury, and Methymercury to Chlorella vulgaris. Environmental Research25 (1981) 250-259

Rice, E.L. Allelopathy. Academic Press, NY. (1984) 353 pp.

Rosko, J. Rachlin, J. The Effect of Cadmium, Copper, Mercury, Zinc, and Lead on Cell Division, Growth, and chlorophyll a Content of the Chlorophyte Chlorella vulgaris. Bulletin of the Torrey Botanical Club 104 (1977) 226-233

Sustainable Development of Algal Biofuels in the United States. Committee on the Sustainable Development of Algal Biofuels. National Research Council (NRC) of the Academies (2012). Retrieved May 20, 2016 from http://www.nap.edu/catalog/13437/sustainable-development-of-algal-biofuels-in-theunited-states

U.S. Department of Energy (DOE). National Algal Biofuels Technology Roadmap (2010). Retrieved May 18, 2016 from https://www1.eere.energy.gov/bioenergy/pdfs/algal_biofuels_roadmap.pdf

Wanq, H. Zhang, W. Chen, L. Wanq, J. Liu, T. The Contamination and Control of BiologicAL Polutants in mass Cultivation of Microalgae. Bioresource Technologies 128 (2013) 745750 
Wychen, S. Ramirez, K. Laurens, L. Determination of Total Lipids as Fatty Acid Methyl Esters (FAME) by in situ Transesterification Laboratory Analytical Procedure. ATP ${ }^{3}$ Algae Testbed (2015)

Wychen, S. Laurens, L. Determination of Total Carbohydrates in Algal Biomass Laboratory Analytical Procedure. ATP ${ }^{3}$ Algae Testbed (2015)

Yamda, N. Murakami, N. Kawamura, N. Sakakibara, J. Mechanism of an Early Lysis by Fatty Acids from Axenic Phormidium tenue (Musty Odor-Producing Cyanobacterium) and Its Growth Prolongation by Bacteria. Biol Pharm Bull. 17 (1994) 1277-1281 


\section{APPENDICES}

\section{Appendix A: Trace Metal Stock Solution used in Modified BG11 Media Recipe}

Table A: Trace metal stock solution for modified BG11 media. $1 \mathrm{~mL}$ of trace metal stock solution is added per liter of media prepared.

\begin{tabular}{ccccc}
\hline Compound name & $\begin{array}{c}\text { Chemical } \\
\text { Formula }\end{array}$ & $\begin{array}{c}\text { Molecular } \\
\text { Weight }\end{array}$ & $\begin{array}{c}\text { Concentration in } \\
\text { stock solution } \\
(\mathrm{g} / \mathrm{L})\end{array}$ & $\begin{array}{c}\text { Concentration in } \\
\text { final medium } \\
(\mathrm{mg} / \mathrm{L})\end{array}$ \\
\hline Boric acid & $\mathrm{H}_{3} \mathrm{BO}_{3}$ & 61.8 & 2.86 & 2.86 \\
\hline $\begin{array}{c}\text { Manganese } \\
\text { chloride } \\
\text { tetrahydrate }\end{array}$ & $\mathrm{MnCl} 2 \cdot 4 \mathrm{H} 2 \mathrm{O}$ & 197.9 & 1.81 & 0.22 \\
\hline $\begin{array}{c}\text { Zinc sulfate } \\
\text { heptahydrate }\end{array}$ & $\mathrm{ZnSO} 4 \cdot 7 \mathrm{H} 2 \mathrm{O}$ & 287.6 & 0.22 & 79.0 \\
\hline $\begin{array}{c}\text { Copper (II) sulfate } \\
\text { pentahydrate }\end{array}$ & $\mathrm{CuSO} 4 \cdot 5 \mathrm{H} 2 \mathrm{O}$ & 249.7 & 79.00 & 0.391 \\
\hline $\begin{array}{c}\text { Sodium molybdate } \\
\text { dihydrate }\end{array}$ & $\mathrm{Na} 2 \mathrm{MoO} 4 \cdot 2 \mathrm{H} 2 \mathrm{O}$ & 241.9 & 0.39 & 49.4 \\
\hline $\begin{array}{c}\text { Cobalt (II) nitrate } \\
\text { hexahydrate }\end{array}$ & $\mathrm{Co}(\mathrm{NO} 3) 2 \cdot 6 \mathrm{H} 2 \mathrm{O}$ & 291.035 & 49.40 & \\
\hline
\end{tabular}

